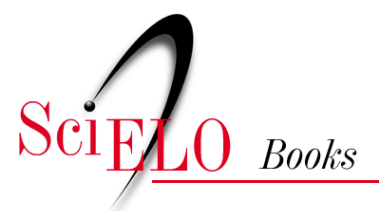

\title{
1. O Pacto Federativo Brasileiro e o papel do gestor estadual no SUS
}

\author{
Luciana Dias de Lima \\ Cristiani Vieira Machado \\ Tatiana Wargas de Faria Baptista \\ Adelyne Maria Mendes Pereira
}

\section{SciELO Books / SciELO Livros / SciELO Libros}

LIMA, L.D., et al. O Pacto Federativo Brasileiro e o papel do gestor estadual no SUS. In: UGÁ, M.A.D., et al., (orgs.). A gestão do SUS no âmbito estadual: o caso do Rio de Janeiro [online]. Rio de Janeiro: Editora FIOCRUZ, 2010, pp. 27-58. ISBN: 978-85-7541-592-4. Available from: doi: $10.7476 / 9788575415924.0003$. Also available in ePUB from: http://books.scielo.org/id/c2hxb/epub/uga-9788575415924.epub.

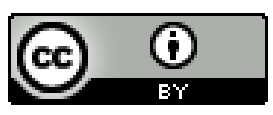

All the contents of this work, except where otherwise noted, is licensed under a Creative Commons Attribution 4.0 International license.

Todo o conteúdo deste trabalho, exceto quando houver ressalva, é publicado sob a licença $\underline{\text { Creative Commons }}$ Atribição 4.0. 


\title{
- Pacto Federativo Brasileiro e o Papel do Gestor Estadual no SUS'
}

\author{
Luciana Dias de Lima \\ Cristiani Vieira Machado \\ Tatiana Wargas de Faria Baptista \\ Adelyne Maria Mendes Pereira
}

No Brasil, o reconhecimento da saúde como direito de cidadania no fim dos anos 80 ocorre justamente quando se colocam novos desafios para as políticas públicas, relacionados aos processos de reforma dos Estados no plano internacional e à constatação da crise do modelo de desenvolvimento e de intervenção estatal hegemônico no país.

Acrescente-se que a análise do papel do Estado assume contornos e desafios próprios nos países federativos, como o Brasil, em que o poder estatal se manifesta em mais de uma esfera de governo. $\mathrm{O}$ estudo de uma política setorial, como a de saúde, requer a consideração tanto das características gerais da federação quanto da peculiaridade do arranjo federativo e do modelo de descentralização daquela política. As profundas mudanças político-institucionais observadas no Brasil nas últimas duas décadas, no que concerne às concepções sobre o papel do Estado na área econômica e social e ao pacto federativo, reiteram a importância de compreender as relações entre essas mudanças e as suas implicações para a política de saúde.

Ainda que na produção acadêmica da área da saúde existam muitos estudos sobre o processo de descentralização político-administrativa e a municipalização nos últimos vinte anos, análises sobre a atuação da esfera estadual na saúde são escassas no Brasil. O aprofundamento desse tema faz-se necessário, uma vez que as instâncias estaduais são fundamentais na configuração do arranjo federativo e na condução das políticas públicas nas distintas federações no mundo. Em outras palavras, enquanto o debate sobre o papel do Estado no âmbito nacional é imprescindível em países com distintas formas de organização territorial de poder - unitária ou federativa -, nas federações a análise das funções desempenhadas pelos estados (províncias, länder, cantões, etc.) constitui elo crucial para a caracterização da essência da federação e para a análise de políticas específicas.

\footnotetext{
${ }^{1}$ A pesquisa que embasou este trabalho foi favorecida pelo apoio financeiro do Conselho Nacional de Desenvolvimento Científico e Tecnológico $(\mathrm{CNPq})$ e da Fundação de Amparo à Pesquisa do Estado do Rio de Janeiro (Faperj).
} 
Este capítulo tem como objetivo trazer elementos para a discussão sobre o papel das instâncias estaduais na política pública de saúde a partir da instituição do Sistema Único de Saúde (SUS). Para isso, busca-se compreender as articulações existentes entre o modelo de intervenção do Estado, o pacto federativo brasileiro e a política setorial.

A próxima sessão trata brevemente das reformas dos Estados no período recente e de sua repercussão no Brasil, enfatizando as alterações nas macrofunções estatais e suas implicações para a saúde. A seguir, são abordadas as especificidades das organizações federativas e suas implicações para as políticas de saúde, a partir da revisão de alguns estudos internacionais e nacionais sobre o tema. No capítulo, ainda são discutidos os dilemas do arranjo federativo brasileiro e das mudanças observadas no pós-1988 para a atuação das esferas estaduais na saúde. Por fim, analisa-se o marco legal e normativo do SUS, com ênfase no papel dos gestores estaduais. Procura-se identificar, no contexto em que essas normativas foram geradas, as mudanças nas funções dos estados e as implicações que tais mudanças trouxeram para sua atuação ao longo dos anos. Nas considerações finais, discutem-se os desafios atuais da gestão estadual no SUS com foco na regionalização.

\section{Modelos de INTERVEnÇÃo Estatal: NOtAS SObRe AS FUnÇÕes do ESTADO NA SAÚDE}

O Estado, na concepção weberiana, pressupõe um conjunto de órgãos, uma burocracia, um ordenamento legal e a estabilização de uma estrutura de autoridade. ${ }^{2}$ As distintas correntes teóricas trazem aportes complementares para a análise do papel do Estado nas políticas públicas, merecendo destaque a contribuição dos autores neomarxistas, do institucionalismo histórico e da análise setorial. ${ }^{3}$ Assim, a compreensão de políticas específicas pode ser mais rica se considerar a articulação de características estruturais do Estado e da sociedade, a importância das regras institucionais, da posição dos atores inseridos em um dado contexto institucional e do processo político, incluindo tanto parâmetros gerais como a consideração de referenciais setoriais.

De acordo com a abordagem de Lenhardt e Offe (1984), a política de saúde, assim como as demais políticas sociais, expressa tanto traços mais gerais do modelo de intervenção do Estado brasileiro quanto características próprias, relacionadas às peculiaridades setoriais. ${ }^{4}$ Neste caso, é necessário considerar, em primeiro lugar, a agenda mais ampla

2 Esses pontos são ressaltados por Almeida (2007).

3 Uma revisão dessas correntes é feita por Marques (1997).

${ }^{4}$ Lenhardt e Offe (1984) indicam que as políticas sociais podem ser analisadas em ao menos dois planos. O primeiro é o plano estrutural, relacionado à sua inserção no Estado capitalista e à ligação com as determinações estruturais. O segundo plano refere-se à singularidade das políticas sociais, ou seja, às peculiaridades que as distinguem de outras políticas nos processos históricos das sociedades. Para esses autores, as políticas sociais não são única e funcionalmente determinadas por uma dada estrutura econômica capitalista. Elas possuem especificidades relacionadas à sua evolução (incluindo modificações e inovações) e à sua relação com as estratégias de racionalização da ação estatal. Em síntese, essa abordagem sugere a necessidade de articulação entre a reflexão mais ampla sobre o papel e modelo de intervenção do Estado (no âmbito deste trabalho, o Estado brasileiro) com a sua atuação nas políticas sociais (particularmente a política de saúde). 
de reforma do Estado no plano internacional, que tem repercussões sobre o país e, em segundo lugar, compreender o papel que as políticas sociais, em especial as de saúde, ocupam no projeto de Estado.

Quanto ao primeiro aspecto, a partir dos anos 70, em face da globalização, ${ }^{5}$ observa-se um questionamento acerca do papel dos Estados Nacionais e o aumento das pressões por mudanças, levando a processos de reforma em diversos países que tiveram como traços marcantes a descentralização e a privatização.

Essa onda de reformas, em um primeiro momento, orientava-se fortemente por uma crença normativa sobre a necessidade de retração do tamanho e das funções dos Estados nas áreas econômica e social. No entanto, como destaca Evans (1993), a partir do final da década de 1980, em um aparente paradoxo, o papel do Estado é central até mesmo para a condução dos programas de ajuste estrutural. Configura-se então uma nova vertente de pensamento sobre o Estado, caracterizada pelo reconhecimento da importância da capacidade de ação estatal, seja no sentido da existência de uma tecnocracia, seja no sentido de consolidação de uma estrutura institucional durável e efetiva.

Assim, o debate se desloca fortemente para a discussão a respeito de qual deve ser o papel e o modelo de intervenção do Estado no novo contexto mundial. Segundo Majone (1999), observa-se, nas décadas de 1980 e 1990, um movimento de substituição do "Estado positivo" - planejador, produtor direto de bens e serviços e empregador - pelo "Estado regulador", ainda que tais mudanças se expressem de forma diferente entre nações e áreas da política, devido às suas diferentes trajetórias históricas e institucionais.

Dada a importância histórica dos Estados na garantia de direitos sociais, tais mudanças têm repercussões importantes para os sistemas de proteção social nos vários países, que conduzem reformas com abrangência e efeitos variáveis. Nos países europeus avançados, que já contavam com Welfare States mais sólidos, há evidências de que as reformas, ainda que relevantes, até o momento não chegaram a desestruturar as bases dos sistemas de proteção social (Ferrera, 1998; Pierson, 2000; Wilensky, 2002). No que diz respeito especificamente aos sistemas de saúde, em muitos desses países, processos de reformas orientados por diretrizes de racionalização e contenção de gastos públicos paradoxalmente têm levado ao fortalecimento da regulação estatal (Figueras et al., 2002).

Já nos países latino-americanos, que tinham sistemas de proteção social segmentados e frágeis, a repercussão das reformas conduzidas a partir da década de 1980 parece ter tido um impacto bastante negativo para as políticas públicas, levando ao agravamento do quadro social e à persistência de marcantes desigualdades sociais (Draibe, 1997). Na área da saúde, as agendas de reforma adotadas em muitos países levaram ao agravamento da segmentação e da fragmentação dos sistemas de saúde e reiteraram as desigualdades no acesso, na utilização de serviços e no financiamento da saúde (Almeida, 2002; Opas, 2007).

\footnotetext{
5 A globalização é aqui compreendida como uma nova formatação do capitalismo mundial, de determinações econômicas, políticas e ideológicas, cujo processo é bastante assimétrico entre países e empresas. Ver a propósito os trabalhos reunidos em Tavares e Fiori (1997) e Fiori (1999).
} 
No Brasil, os anos 80 foram marcados pela crise do desenvolvimentismo conservador e pela democratização, com a esperança de construção de um novo pacto político, econômico e social expresso no contexto da Nova República e na Assembleia Nacional Constituinte de 1987-1988. Após a virada conservadora do final da década, os anos 90 são caracterizados pela liberalização econômica e pela democratização (Sallum Jr., 2004), com o predomínio de uma agenda de reforma estatal que visou a desmontar o modelo de intervenção econômica e social conformado na 'era Vargas', norteando-se pela redução do tamanho da administração pública e de seu papel de prestação direta de serviços (Santos, 2006).

Boschi e Lima (2003) identificam uma mudança expressiva no padrão de atuação do Estado, mas ressaltam como um traço comum entre o novo modelo e o anterior a face demiúrgica da atividade regulatória do Executivo, mais evidente no âmbito nacional, denominando-o de "novo intervencionismo regulatório". Os autores advertem ainda que tal marco de atuação estatal é orientado para o mercado, estabelecendo um fosso na relação com os cidadãos, transformados em consumidores pela limitada capacidade de intervenção do Estado nas políticas sociais.

Mais recentemente, ao analisar a atuação do Governo Lula na área econômica, Boschi (2007) identifica um neointervencionismo estatal que se diferencia tanto do modelo dos anos 50 como daquele do Governo Fernando Henrique Cardoso. O modelo atual se caracteriza por certa retomada das iniciativas de desenvolvimento em longo prazo sob forte coordenação estatal, com maior espaço para as atividades de regulação e controle e com esquemas de intervenção na área da produção que ocupam papel estratégico.

Para compreensão do papel e da atuação do Estado na saúde no período recente, é útil recorrer, ainda, à noção de 'funções de Estado na saúde', cujas características e cuja articulação conformam um dado modelo de intervenção estatal no setor. Resumidamente, as quatro macrofunções de Estado na saúde são:

- 'Formulação de políticas e planejamento' - constituem funções fundamentais para o direcionamento da política de saúde, que envolvem a tomada de decisões e a proposição de intervenções sobre a realidade sanitária, abrangendo a identificação de necessidades, de prioridades e diretrizes de ação; a elaboração de estratégias e planos de intervenção; a articulação com outros atores e mobilização de recursos necessários para a operacionalização das políticas.

- 'Financiamento' - está relacionado à capacidade do Estado em garantir os recursos financeiros necessários à materialização dos direitos à saúde, envolvendo uma dimensão redistributiva. A função estatal de financiamento pode ser analisada em vários âmbitos, tais como o comprometimento do gasto público com a saúde; a magnitude do gasto público em saúde; a participação pública no gasto total em saúde (em relação ao gasto privado); o sistema de partilha fiscal (incluindo as transferências intergovernamentais na saúde) e a distribuição do gasto público entre esferas de governo (em países federativos); as prioridades do gasto público em saúde; o caráter redistributivo dos gastos (entre regiões e entre grupos sociais em um país); a gestão orçamentária e financeira dos recursos da saúde. 
- 'Regulação' - mesmo existindo diferentes concepções a seu respeito, considera-se que a função de regulação do Estado na saúde envolve quatro âmbitos principais (Machado, 2007): a regulação sobre prestadores de serviços; a regulação de sistemas de saúde; a regulação sanitária; a regulação de mercados em saúde. Nestes âmbitos, incluem-se a adoção de um conjunto de estratégias voltadas para a regulamentação, coordenação e avaliação das ações, bens, serviços e sistemas de saúde, visando a controlar procedimentos e processos, induzir e assegurar determinadas características comuns e resultados mais uniformes.

- 'Prestação de serviços' - expressa a responsabilidade pela provisão de ações e serviços de saúde que pode estar dividida entre vários agentes, governamentais e não governamentais. A prestação direta de serviços pelo Estado requer a existência de quadros próprios de funcionários e uma série de funções administrativas, relativas à gestão de pessoal, de compras, armazenamento e distribuição de insumos, organização e operação dos serviços próprios de saúde.

Ainda que a saúde seja influenciada por diversas políticas públicas, as funções de Estado no âmbito setorial são, em sua maior parte, exercidas pelas autoridades sanitárias no país. Dada a trajetória dual da política de saúde brasileira, ${ }^{6}$ ao longo do século XX tais funções foram exercidas por diferentes organismos estatais em cada esfera de governo, com características variadas. Acrescente-se a isso a predominância de um modelo centralizador na condução das políticas nacionais de saúde, seja na vertente da saúde pública, seja na previdenciária, coerente com a cultura política presente na federação e as características mais gerais dos regimes autoritários que vigoraram na maior parte do período pós-1930.

A agenda da Reforma Sanitária brasileira dos anos 80 e as concepções que constam da Constituição Federal de 1988 (CF88) relativas à seguridade social e ao SUS pressupunham um modelo de atuação estatal na saúde diferente do anterior, reafirmando o dever do Estado na garantia do direito à saúde e recolocando a questão federativa no centro do debate. No entanto, a atuação do Estado na implantação do SUS nos anos 90 foi pressionada também pela agenda liberal de reformas hegemônicas na década, sendo o modelo de intervenção estatal na saúde influenciado por essas duas agendas conflitantes.

A consolidação do SUS, as transformações do Estado e a descentralização políticoadministrativa condicionaram o papel das novas autoridades sanitárias - o Ministério da Saúde pós-incorporação do Instituto Nacional de Assistência Médica da Previdência Social (Inamps), as secretarias estaduais e as milhares de secretarias municipais de saúde - nos últimos vinte anos, exigindo mudanças nas funções, atribuições, na estrutura e

\footnotetext{
6 A trajetória dual se caracteriza pela dicotomia histórica das políticas de saúde no Brasil, marcante dos anos 30 aos anos 80, com expressões no âmbito das instituições e do direito à saúde. Tal dicotomia se expressou, de um lado, na construção de uma saúde pública voltada para o controle do ambiente e das doenças e, de outro, na expansão da assistência médica previdenciária voltada para a parcela da população trabalhadora e contribuinte do sistema. Sobre esta discussão, ver Fonseca (2007).
} 
lógica de atuação dos gestores da saúde. O Ministério da Saúde continuou a ter uma função importante na condução da política nacional de saúde, por meio da indução e regulação de políticas, exercendo seu poder sobre outras esferas de governo, prestadores de serviços e alguns mercados em saúde (Machado, 2007). Os municípios ganharam imenso destaque na política de saúde devido ao aumento de suas responsabilidades no planejamento, no financiamento, na regulação e na prestação direta de serviços de saúde no âmbito local.

A definição de um novo papel da esfera estadual na saúde, no entanto, apresentou uma série de dificuldades e continua a representar um dos maiores desafios do pacto federativo na saúde.

\section{As Especificidades das Organizações Federativas e suas Implicações para as Políticas de Saúde}

A importância da compreensão do papel da esfera estadual na construção das políticas públicas em Estados federativos é um argumento-chave que permeia a discussão deste capítulo. Nesse sentido, torna-se imprescindível uma rápida explanação das especificidades dos arranjos federativos em face das demais formas de organização do Estado existentes. Menos para constituir um modelo único de federação que enquadre os diferentes casos, e mais para iluminar aspectos pertinentes a esse modelo que sirvam como parâmetros para análise dos países que assumem a proposta federativa.

Uma primeira distinção a ser feita diz respeito ao arranjo político mais geral que diferencia as organizações federativas do modelo unitário. Enquanto nos países unitários há uma relação hierárquica de poder estabelecida com os níveis subnacionais de governo, no modelo federativo há uma repartição da autoridade política do Estado, e o exercício do poder se efetiva em múltiplos centros soberanos definidos geograficamente e coordenados entre si (Abrucio, 2003). Ou seja, nas federações, independentemente de como os poderes estejam repartidos, os governos nacional e subnacionais possuem certa autonomia em sua esfera de atuação e decisão final e sua autoridade não pode ser retirada sem consentimento mútuo (Lima, 2007). Isso significa que, no federalismo, nenhum estado membro da federação tem o direito de renunciar unilateralmente ao pacto político ou rejeitar uma lei emitida pelo Congresso Nacional e legitimada pelo Judiciário. ${ }^{7}$ Em contrapartida, o governo federal não pode obrigar os demais entes a fazer qualquer ação, bem como realizar ações no território estadual (ou municipal, no caso brasileiro) que rompam com o pacto constitucionalmente estabelecido (Costa, 2004).

A conformação desse modelo se deu de forma bem distinta nos países, e cada realidade constituiu variações nas organizações político-institucionais, o que também tem contribuído para a construção de uma variedade de abordagens teóricas e controvérsias em

\footnotetext{
Em geral, nas organizações federativas há uma combinação do princípio da representação popular com uma divisão matricial do poder. De um lado, o poder é partido entre o Executivo, o Legislativo e o Judiciário. De outro, distribuem-se as responsabilidades de governo entre a União e os demais entes, de forma que um não pode interferir nas diretrizes do outro sem autorização política ou judicial (Costa, 2004).
} 
torno do tema do federalismo. ${ }^{8}$ Assim, a compreensão de uma organização federativa deve considerar a história, os arranjos políticos e a especificidade de cada país na construção de seus modelos.

Soares (1998) ressalta as disputas e pressões por autonomia política local em contextos marcados por heterogeneidade de bases territoriais como aspectos importantes da gênese dos arranjos federativos. Nesses contextos, o federalismo surge como uma resposta ao problema de constituir e manter um Estado Nacional, intermediando interesses locais, que, como veremos, se aproximam da trajetória de construção do federalismo brasileiro.

Para Burgess (1993), o federalismo é um conceito de valor, sintetizado pelo duo "unidade na diversidade”, que informa a federação tanto como recomendação ideológica e filosófica como prática, através do reconhecimento da sociedade, de suas heterogeneidades e do desenho de suas próprias instituições.

Um conceito comumente aceito de federalismo é aquele que o define como um conjunto de instituições políticas que dão forma à combinação de dois princípios básicos: autonomia dos governos e interdependência entre eles (Elazar, 1987). O princípio de autonomia é aquele por meio do qual os entes federativos estabelecem suas regras de autogoverno ("self rule") e delimitam o raio de ação do poder de outros níveis de governo sobre suas instâncias. O princípio da interdependência ("shared rule") define os padrões de cooperação dentro da federação, os quais estabelecem uma prática de negociação capaz de traçar metas comuns entre os governos. A interdependência fala a favor de uma complementaridade entre as esferas de governo, a necessidade de reforçar laços federativos e de se criar parâmetros nacionais, respeitando as diversidades loco-regionais e diminuindo os riscos de desagregação.

Há nesses dois princípios uma antinomia que traz complexidade às organizações federativas, pois se trata de, ao mesmo tempo, conciliar os interesses dos entes federativos com aqueles que constituem o projeto de Estado de uma Nação. Em um Estado federativo este projeto implicará harmonizar três ideias básicas - igualdade, integridade/ autonomia e cooperação, em um ambiente onde o poder se dispersa em múltiplos centros que possuem garantias constitucionais para o exercício do poder autônomo - numa estrutura não centralizada por definição, o que também coloca o desafio da soberania compartilhada.

No que tange especificamente à descentralização, Abrucio (2005) ressalta a importância da busca de um equilíbrio entre os processos de descentralização e centralização nas federações, entendidos como complementares e não antagônicos. Para o autor, a descentralização exige um projeto nacional acordado, submetido a várias rodadas de negociação, e a construção de capacidades tanto dos governos subnacionais quanto do governo nacional,

\footnotetext{
8 Almeida (2001) salienta a diversidade de abordagens possíveis sobre o federalismo - histórica, econômica, jurídica, política - e faz um balanço dos principais autores no âmbito da ciência política, destacando o federalismo como um campo temático ainda em desenvolvimento e a dificuldade de estabelecimento de consensos mínimos.
} 
o que envolve jogos de cooperação e competição, acordos, vetos e decisões conjuntas entre níveis de governo.

Assim, o que este modelo evoca é a construção de uma habilidade e a capacidade de negociação dos entes governamentais envolvidos, exigindo coordenação intergovernamental e constituição de mecanismos de controle mútuos entre governos. As relações intergovernamentais são peças-chave na organização federativa, pois é a partir delas que se estabelecerá a divisão de competências e de responsabilidades entre os níveis de governo no plano das políticas públicas específicas, bem como a repartição de poder econômico-financeiro entre os diferentes níveis de governo. Por tudo isso é importante conhecer o projeto de Estado em que se baseiam os arranjos federativos, compreender o papel que os entes nacional e subnacionais exercem na orientação das políticas no território e as formas de relação estabelecidas entre eles. Essas são questões fundamentais quando o foco de análise são os modelos de sistemas de saúde que se estabelecem historicamente nos países e suas relações com os diferentes arranjos político-institucionais nos Estados.

A literatura que aborda a construção e evolução dos sistemas de saúde, de âmbito universal e abrangente, indica o importante papel dos governos centrais na consolidação desses sistemas, fortemente baseados nos valores de solidariedade e cidadania social. Contudo, nos países federativos, pode existir uma tensão entre o caráter nacional da política de saúde e o respeito às autonomias e diversidades territoriais requeridos pelas esferas regionais e locais (France, 2002).

Banting e Corbett (2002) consideram o federalismo compatível com distintos modelos de sistemas de saúde, cuja variação reflete a combinação de interesses econômicos, ideologias políticas, normas e valores culturais subjacentes aos países. Em que pese a importância de arranjos e instrumentos institucionais, o federalismo não pode ser entendido como fator isolado e determinante do sucesso ou fracasso das políticas de saúde adotadas, que devem ser compreendidas à luz do projeto político de Estado que norteia sua ação na saúde.

Por todos os aspectos mencionados, depreende-se que a configuração de políticas nacionais de saúde torna-se ainda mais complexa nas seguintes situações:

- em federações marcadas por grande heterogeneidade, com desigualdade de poder político, econômico, social e institucional;

- quando o projeto político federativo não é claro para todos ou é o projeto de alguns que querem manter o poder;

- em realidades que experimentaram trajetórias políticas majoritariamente centralizadoras, não gerando capacidade político-institucional nas esferas subnacionais.

Esses três elementos se apresentam na trajetória do Estado federativo brasileiro e somam implicações e desafios para a configuração do papel das esferas estaduais na consolidação do SUS. 


\section{O Pacto Federativo Brasileiro: dilemas institucionais para a ATUAÇÃO DA ESFERA ESTADUAL}

A análise histórica do federalismo no Brasil sugere que os conflitos políticos relacionados à divisão territorial do poder tiveram início no período colonial (Carvalho, 1996) e que as origens do pacto federativo remontam ao Império, quando são explicitados os poderes administrativos às então 16 províncias existentes, bem como suas competências relativas à tributação, à força policial e à participação nos processos decisórios nacionais (Dolhnikoff, 2005). No entanto, sua instauração formal se deu com a promulgação da primeira Constituição Federal Republicana em 1891. A adoção dessa forma de organização do Estado esteve relacionada à ideia de permitir maior descentralização e autonomia, face ao descontentamento das elites regionais com a centralização monárquica, buscando "manter junto" um país com fortes tradições localistas e heterogeneidades (Almeida, 2001). ${ }^{9}$

Entretanto, somente esse aspecto é insuficiente para compreender a conformação da federação brasileira. Abrucio (2003) argumenta que o federalismo no Brasil também se diferencia pela ausência do republicanismo na base do sistema político, pois o fim da Monarquia respondeu mais aos anseios por descentralização do poder do que pela democratização da política. Para esse autor, a instauração da República subordina-se a um "certo ideal federativo" quando, em vez de descentralizar redesenhando a forma de atuação da esfera nacional, enfraquecemo-la em prol da maior autonomia e riqueza proclamada por alguns estados (principalmente São Paulo e Minas Gerais) e do fortalecimento de oligarquias que dominavam a política local.

Isso permitiu ao governo central, ainda que limitado, atender a interesses políticos e econômicos loco-regionais, por meio da canalização de recursos para poucas unidades territoriais, onde foram mantidas escassas as relações entre os entes da federação, em detrimento de um projeto de construção estatal nacional e abrangente. Nosso federalismo, portanto, nasce de modo centrífugo e hierárquico, mas também assimétrico e oligárquico no plano subnacional.

Ao longo da história, observa-se a alternância entre períodos de centralização e descentralização, relacionados aos regimes autoritários e à vigência da ordem democrática, que alteraram as relações de poder entre a União, os estados e os governos locais. ${ }^{10} \mathrm{Em}$ seu estudo já clássico sobre o tema, Abrucio (1998) destaca o longo período do "unionismo autoritário" no Brasil, que vigorou como forma de relação intergovernamental na ditadura militar, ${ }^{11}$ seguido pela conformação, nos anos 80, de um arranjo "estadualista", consolidado com as eleições diretas para os governos estaduais e a vitória da oposição em 1982.

\footnotetext{
9 Stepan (1999) buscou confrontar duas lógicas distintas que atuam na origem das federações: o federalismo como um arranjo político no qual se juntam unidades político territoriais com autoridade previamente existente ("come together"); o federalismo como um arranjo que mantém juntas unidades territoriais que poderiam aspirar trajetórias independentes ("hold together").

${ }^{10}$ A periodização do federalismo no Brasil já foi objeto de diversos trabalhos, com objetivos e perspectivas de análise distintas. Entre outros, Abrucio (1998); Kugelmas e Sola (1999); Viana, Lima e Oliveira (2002).

${ }^{11}$ Este modelo firma-se sobre três pilares: o financeiro, o administrativo e o político. A centralização de receitas pelo Executivo, a uniformização administrativa nas três esferas de governo e o controle das eleições dos governadores asseguravam a predominância da União sobre os demais entes federados.
} 
Esse modelo, em que o Executivo perdeu forças para o Congresso Nacional e a União, para os estados, surge pelo fortalecimento do poder dos governadores, assentado sobre: a coincidência temporal entre as crises do Estado desenvolvimentista e a do regime militar, aliada ao contínuo crescimento financeiro das unidades subnacionais; o papel dos governadores na transição democrática; a importância das eleições estaduais no sistema político-eleitoral (tanto em relação à Presidência, como também às assembleias legislativas e às prefeituras municipais); a crise do presidencialismo brasileiro durante a década de 1980 e início dos anos 90.

Alguns estudos tendem a enfatizar os aspectos negativos desse arranjo, que ainda dificultam a formulação e a implementação das políticas públicas diante da situação de ingovernabilidade gerada e do movimento predatório dos estados (Abrucio \& Samuels, 1997; Abrucio, 1998, 2001). No entanto, esse diagnóstico não é consensual entre os cientistas políticos que se dedicam ao tema.

Almeida (2001) concorda com a tese de Abrucio de que os estados são atores políticos historicamente importantes, que exercem influência sobre suas bancadas no Congresso, sobre as eleições municipais e a conformação dos partidos, o que os torna, na metáfora utilizada por Abrucio, verdadeiros "barões da federação". No entanto, pondera a falta de evidências que sustentem a afirmação de que o acúmulo de poder dos governadores os tenha transformado necessariamente em "jogadores com poder de veto" durante o período democrático, dificultando a realização da agenda de reformas pelo Executivo.

Um olhar minucioso sobre os anos 90 mostra que foi possível implementar um programa amplo de estabilização econômica, encaminhar importantes reformas constitucionais e estabelecer limitações fiscais aos entes subnacionais a despeito do recrudescimento do poder dos estados na década anterior. Alguns autores assinalam que a extensão dos recursos de poder da Presidência da República no Brasil, auferida pela soma de poderes acumulada por sua tecnoburocracia (Kugelmas \& Sola, 1999), e a visão centralizadora que predomina em nossa cultura política (Almeida, 2005) ajudam a compreender a importância da União perante os demais entes governamentais.

Se o curto período "estadualista" em nossa federação existiu durante a redemocratização, é possível afirmar que ele entrou em crise ainda na primeira metade da década seguinte em função de uma série de mudanças decorrentes da própria Constituição de 1988 (CF88), das prioridades federais e das condições políticas e econômicas do período recente. Tais mudanças alteraram o funcionamento das instituições federativas brasileiras, nas dimensões política, fiscal e organizacional, com implicações para as relações intergovernamentais e para atuação da esfera estadual.

Em primeiro lugar, destaca-se 'o fortalecimento dos municípios no sistema político nacional', transformados em entes federativos com o mesmo status jurídico-constitucional que os estados e a União, tendo suas competências e prerrogativas asseguradas por força da Lei Constitucional e do Poder Judiciário.12 O Brasil, portanto, diferentemente das

\footnotetext{
${ }^{12}$ A CF88, em seu art. 18, define que "a organização político-administrativa no Brasil compreende a União, os Estados, o Distrito Federal e os Municípios, todos autônomos nos termos da Constituição” (Brasil, 1988).
} 
demais federações existentes no mundo, possui soberania partilhada por três esferas de governo, refletindo uma longa tradição do poder local no país. ${ }^{13} \mathrm{O}$ reconhecimento dos municípios como entes federativos foi também acompanhado por um processo importante de ampliação e descentralização de encargos sociais e recursos fiscais, e intensificação do processo de emancipação de novos municípios.

Observa-se que os governos locais são igualmente responsáveis por grande parte das políticas públicas, definidas como competências comuns aos três entes na CF88, entre elas: saúde e assistência pública; assistência aos portadores de deficiência; cultura, educação e ciência; habitação e saneamento; proteção ao meio ambiente e aos recursos naturais (Brasil, 1988).

Em relação à descentralização tributária, estimativas efetuadas indicam que a participação da União na receita disponível caiu de 64,1\% em 1987, para 56,7\% em 2000. Enquanto isso, no mesmo período, os estados aumentaram sua fatia de $23,3 \%$ para 26,4\% e os municípios, de 12,6\% para 16,9\% (Rezende \& Afonso, 2001). Os municípios foram os principais beneficiados pela ampliação de tributos, pois, assim como a União, os estados, que desempenham importante função na arrecadação total do país em virtude de sua competência sobre o Imposto sobre Circulação de Mercadorias e Serviços (ICMS), arrecadam relativamente maior parcela de receita fiscal do que lhes resta no orçamento após as transferências intergovernamentais. ${ }^{14}$

A prerrogativa dos municípios na descentralização de receitas se deve à ampliação de suas competências tributárias e ao aumento das transferências obrigatórias da União e dos estados na CF88. Das receitas totais cedidas pelo governo federal, a maior parte vai para as jurisdições locais por meio do Fundo de Participação dos Municípios (FPM). Em relação aos estados, Prado (2003) estima que cerca de 30\% de suas receitas são transferidas aos municípios, incluindo 25\% do ICMS, 50\% do Imposto sobre Veículos Automotores (IPVA) arrecadados e 25\% do IPI-Exportação recebido da União.

Sobre a criação de novos municípios, levantamentos efetuados indicam que no período entre 1980 e 2001 foram instalados 1.570 municípios no país (Bremaeker, 2001). ${ }^{15}$

13 Souza (2005) enfatiza esse aspecto ao analisar a forma como o federalismo foi desenhado nas sete constituições que regeram as instituições brasileiras após a promulgação da República, acentuando o processo de descentralização administrativa e fiscal ocorrido para os municípios em períodos que precederam a CF88. Além disso, o movimento municipalista no Brasil ganhou contornos mais nítidos nos anos 80 constituindo-se num ator organizado nos debates políticos. Em 1980, foi fundada a Confederação Nacional dos Municípios. No âmbito da saúde, desde a década de 1970 um conjunto de eventos municipalistas, associados ao movimento de reforma do setor saúde, possibilitou o início da institucionalização do movimento e sua consolidação nos anos 80 e 90 (Goulart, 1996).

${ }^{14}$ Em 1988, houve o aumento da abrangência do antigo Imposto sobre Circulação de Mercadorias (ICM), sob competência dos estados, com a criação do ICMS. O ICMS inclui impostos que anteriormente eram de competência da União (sobre combustíveis, energia elétrica, minerais, comunicação e transportes). Entretanto, algumas alterações do sistema tributário na CF88 comprometeram a arrecadação total dos estados, como a não incorporação do Imposto sobre Serviços, mantido sobre competência dos municípios no ICMS, o compartilhamento com os governos locais do antigo imposto sobre a transmissão de bens imóveis e a desoneração fiscal das exportações promovida pelo Fundo de Compensação pela Exportação de Produtos Industrializados (IPI-Exportação) (Rezende, 2003).

15 Segundo Bremaeker (2001), 31,8\% deles entre 1980 e 1991, 30,8\% em 1993, 34,0\% em 1997 e 3,4\% em 2001. Entre as Unidades da Federação, aquelas que apresentaram maior número de novos municípios, 
Atualmente, existem 5.563 municípios, sendo que mais de $75 \%$ possuem menos de 25.000 habitantes. Esse fenômeno, que não é novo, é decorrente tanto das regras de partilha do FPM ${ }^{16}$ como resultante da regulamentação sobre a criação, incorporação, fusão e o desmembramento de governos locais. ${ }^{17}$

A descentralização 'municipalista' fortalece, na arena política, os atores municipais e coloca novos desafios para os processos de condução política a cargo das instâncias estaduais. Por um lado, abre possibilidades de transformação da relação Estado e sociedade e de maior experimentação no campo das políticas públicas em nível local. Por outro, sabe-se que a maioria dos municípios brasileiros (os de pequeno porte populacional) não tem arrecadação própria significativa e depende das transferências intergovernamentais de recursos, com limitada capacidade de aumentar seu grau de autonomia política e financeira a partir do processo de descentralização (Prado, Quadros \& Cavalcanti, 2003; Lima, 2007). Os gastos per capita com a manutenção dos quadros legislativos nas pequenas localidades, por vezes, superam as despesas com as políticas sociais (Gomes \& MacDowell, 2000), e muitos municípios têm dificuldades administrativas, de formação e fixação de quadros públicos qualificados, o que limita as condições para o exercício dos governos locais (Souza, 2002).

Ressalta-se que, com exceção da educação, que possui um dispositivo de transferência compartilhada entre os governos (o Fundo de Manutenção e Desenvolvimento da Educação Básica e de Valorização dos Profissionais da Educação - Fundeb), as relações fiscais predominantes, gerais e setoriais, se dão entre a União e os municípios, sendo pouco intermediadas pelos estados. As transferências estaduais, efetuadas por meio do ICMS, são particularmente importantes para as cidades médias e grandes, áreas com enormes carências, e onde vive a maior parcela da população. Entretanto, enquanto os principais mecanismos de transferência tributária adotados pelo governo federal são de natureza redistributiva (o FPM e as transferências automáticas do SUS), prepondera nas transferências regulares dos governos estaduais a devolução tributária ( $90 \%$ dos recursos totais transferidos). Isso acaba por restringir os instrumentos legais, a cargo dos governos estaduais, que possibilitariam a compensação financeira e a diminuição das desigualdades na capacidade de gasto dos municípios.

Cabe ainda salientar que o elevado número de municípios no Brasil favorece a "pulverização da representação política” (Dain, 1995), tornando mais complexo o processo de

no período entre 1980 e 2001, foram: Rio Grande do Sul (16,9\% do conjunto brasileiro); Minas Gerais (8,3\%); Paraná e Piauí (6,9\% cada); Santa Catarina (6,1\%); Tocantins e Maranhão (5,5\% cada); Mato Grosso (5,4\%); Bahia (5,2\%); Goiás (4,8\%); São Paulo (4,7\%); e Pará e Paraíba (3,8\% cada).

${ }_{16}$ O desdobramento de um município, ao ratear sua base populacional, coloca-o em uma faixa populacional que atribui a ele um coeficiente de rateio relativamente mais favorável à apropriação dos recursos do FPM. Pela quantidade de recursos que o fundo mobiliza, Dain (1995) pondera a existência no país de um incentivo financeiro potente à emancipação de pequenos municípios.

${ }^{17}$ Inicialmente, a Constituição definia que a criação de municípios deveria obedecer à legislação estadual e referendo da população diretamente interessada mediante a realização de plebiscito. Após a promulgação da Emenda Constitucional n.15, de 13 de setembro de 1996, novos municípios só são permitidos após divulgação dos Estudos de Viabilidade Municipal, apresentados e publicados na forma da lei. 
formulação e de implementação de políticas públicas no âmbito estadual. Além disso, tal como alertam Daniel e Somekh (2001), a ideia da descentralização como sinônimo de municipalização induz a um pensamento autárquico que pressupõe que os governos locais possam equacionar sozinhos suas próprias dificuldades. Essa visão equivocada estimula mais a disputa do que a conformação de estratégias e de instrumentos de parceria entre os governos. Para o SUS, em que a cooperação é condição fundamental para otimização do uso de serviços voltados para problemas de ação coletiva que extravasam às fronteiras político-administrativas da federação, a competição desmedida entre os governos locais acaba comprometendo a própria configuração do sistema no território.

Um segundo aspecto importante a ser considerado diz respeito às 'condições de financiamento dos estados no pós-1988'. A análise da década de 1990 demonstra que a descentralização tributária era incoerente, sobretudo, com o modelo de atuação do Estado na economia e na proteção social desenhado após a inflexão conservadora nos anos seguintes à Constituição. A descentralização associada à ampliação dos encargos sociais colidiu diretamente com os objetivos de liberalização econômica e de retração do Estado, pois os investimentos e o aumento dos gastos públicos necessários à universalização da cobertura de serviços essenciais, como os da saúde, eram incompatíveis com o equilíbrio fiscal..$^{18}$ Assim, foi necessário estabelecer formas para reapropriação de recursos e controle sobre os gastos para evitar uma ampliação ainda maior da transferência de recursos e das despesas públicas nos estados e municípios.

Vários foram os mecanismos utilizados pela União para recompor suas receitas tributárias e controlar o déficit fiscal decorrente dos aumentos das despesas nas esferas subnacionais de governo. Entre eles, destacam-se: a ampliação e o contingenciamento das contribuições sociais que deveriam ser destinadas ao financiamento da seguridade social; o corte nos investimentos públicos federais; a implantação de condicionalidades para o repasse de recursos e renegociações da dívida pública com a União; as restrições sobre a gestão de recursos fiscais no nível subnacional.

Tais medidas incidiram nos orçamentos municipais e estaduais e no financiamento da saúde, frustrando as expectativas de maiores benefícios associados à descentralização (Lima, 2007). No entanto, no caso dos estados, tiveram um impacto financeiro mais significativo, tendo em vista o alto grau de endividamento desses entes bem como às formas de renegociação do estoque de suas dívidas promovidas pelo governo federal.

No princípio dos anos 90, quando a preocupação com o déficit público tornou-se elemento central da política econômica, os governos estaduais já se encontravam endivi-

\footnotetext{
${ }^{18}$ Varsano (1996) indica que os estados e municípios, ainda que favorecidos pelo aumento de receita tributária, continuaram com dificuldades financeiras diante de suas dividas passadas e do aumento de suas despesas correntes. Entre 1988 e 1990, verifica-se que os governos estaduais aumentaram cerca de 2\% do PIB de sua receita disponível, despendendo cerca de $74 \%$ desse ganho com pagamento de pessoal. Nos municípios, $30 \%$ da receita adicional foram gastos com aumentos de salários. As principais fontes de despesa foram justamente as áreas de saúde e educação, para quais as responsabilidades dessas instâncias ampliaram-se e onde ocorreram transferências importantes de equipamentos e serviços, além de grandes gastos com o funcionalismo público.
} 
dados por problemas herdados do passado. ${ }^{19}$ Inicialmente, o ajuste de suas contas fiscais era feito por meio do congelamento de salários, do adiamento da execução de despesas orçamentárias, da indexação das receitas à inflação e da obtenção de empréstimos junto a suas instituições financeiras. Com a estabilidade, essas estratégias tornaram-se ineficazes, enquanto as altas taxas de juros utilizadas para conter a inflação tornaram a economia menos dinâmica e incidiram sobre a arrecadação tributária.

Em contrapartida, as estratégias montadas pelo governo federal para limitar as despesas estaduais implicaram amplo programa de 'saneamento financeiro' atrelado à renegociação de suas dívidas. ${ }^{20}$ As metas estabelecidas pelo programa de refinanciamento impuseram um enorme esforço fiscal aos estados, de modo a manter o equilíbrio de suas contas e, simultaneamente, arcar com as taxas elevadas de juros e amortização de parte das dívidas. A tarefa tornou-se ainda mais complexa devido às condições desfavoráveis para conseguir novos empréstimos e ao fraco comportamento da arrecadação, agravada pela aprovação da lei Kandir em 1996 (que desonera as exportações de produtos primários e semielaborados) e pelo baixo crescimento da economia.

Durante os anos 90, na esteira do abandono, pelo governo federal, das políticas de desenvolvimento regional, os estados passaram a utilizar seu poder de gestão sobre as alíquotas do ICMS como instrumento de política econômica, em prejuízo à arrecadação, com o objetivo de atrair novos investimentos e de promover o desenvolvimento industrial, configurando o fenômeno de 'guerra fiscal'. ${ }^{21}$

Prado e Cavalcanti (2000) indicam que a nova onda de investimentos privados nacionais e estrangeiros que se formou nesta época no Brasil impulsionou a disputa interestadual. Estados menos desenvolvidos, temendo perder investimentos em consequência das melhores condições dos principais centros industriais do país, passaram a oferecer maiores incentivos. No entanto, segundo os autores, essa disputa prejudica a todos, pois:

- devido ao princípio misto de origem-destino aplicado ao ICMS, o peso dos benefícios concedidos é suportado, de fato, pelos estados onde o bem é consumido;

- visto que os investidores circulam em busca de concessões ainda mais vantajosas e, em face das ameaças de mudança de localização, os conflitos federativos tendem a acirrar-se;

- com todos os estados engajados na disputa, os benefícios tendem a se igualar e perdem sua eficácia como instrumento de política econômica. As decisões dos investidores voltam ao básico: boa infraestrutura e boas condições socioeconômicas.

19 Segundo Lopreato (2000), o endividamento dos governos estaduais originou-se entre os anos 60 e 70, quando as operações de crédito funcionaram como mecanismo de financiamento desses entes no modelo de desenvolvimento que marcou a ditadura.

${ }^{20}$ A partir de 1995, o programa envolveu reformas do setor público visando à contração das despesas correntes e ajuste patrimonial, incluindo privatização de empresas estatais. Para uma discussão aprofundada do processo de endividamento dos estados e das estratégias de renegociação de suas dívidas, consultar Mora (1998), Lopreato (2000) e Mora e Varsano (2001).

${ }^{21} \mathrm{O}$ manejo das alíquotas do ICMS para atrair investimentos quando praticado sem a aprovação do conjunto dos estados é considerado ilegal no Brasil. No entanto, a falta de mecanismos regulatórios satisfatórios e a atuação do próprio Conselho Nacional de Política Fazendária (Confaz), composto pelos secretários de Fazenda dos estados, acabaram acentuando sua ocorrência. 
Como os estados menos desenvolvidos reduzem sua capacidade de financiamento público, e com a falta de uma política regional patrocinada pelo governo central, as disparidades territoriais aumentam.

A partir de 2000, a Lei de Responsabilidade Fiscal (LRF) estabelece condições duras a serem observadas na gestão das contas públicas das diferentes esferas de governo e nos três Poderes para sustentar a disciplina fiscal (Brasil, 2000a). A lei enfatiza a transparência como condição para aumentar o controle dos contribuintes sobre as ações. Dentre os dispositivos de maior impacto para a gestão subnacional, destaca-se o limite de comprometimento da receita corrente líquida com o pagamento de pessoal, fixado em $60 \%$ para estados e municípios. O não cumprimento das obrigações leva a várias penalidades, inclusive incriminações pessoais.

Segundo Lopreato (2000), diante das limitações financeiras e das pressões para o ajuste fiscal, os estados "perdem capacidade de atuação". É somente a partir de 2004, que os estados voltam a recuperar a sua capacidade de gasto devido ao crescimento econômico que se reflete nas receitas fiscais arrecadadas (principalmente o ICMS) e na geração de superávits. Entretanto, as restrições aqui destacadas não podem ser desconsideradas quando se analisa o frágil desempenho dos estados em relação às suas despesas próprias com ações e serviços públicos de saúde e o descumprimento ainda frequente em relação aos dispositivos da Emenda Constitucional 29 (Mesquita, 2008).

Um terceiro elemento que tensiona a atuação dos estados refere-se ao 'predomínio de competências comuns aos três entes no terreno das políticas sociais' (art. 23) 'e ao caráter concorrente da União e dos estados no que diz respeito à temática legislativa' (art. 24), 22 'associado à insuficiência dos mecanismos de coordenação federativa existentes' (Brasil, 1988).

No Brasil, optou-se por uma modalidade de federalismo cooperativo, que introduz a possibilidade de execução conjunta e admite a participação de mais de uma esfera política nas tarefas governamentais (Dallari, 1995). De acordo com Almeida (2001), esse padrão é comum em diversas federações do mundo, permitindo uma maior flexibilidade na distribuição de responsabilidades em situações de expressivas desigualdades, como é a brasileira. Simultaneamente, o constituinte remeteu à formulação posterior de uma lei complementar a responsabilidade sobre a fixação de normas para a cooperação intergovernamental.

$\mathrm{Na}$ falta da promulgação desta lei, as políticas sociais, no âmbito de sua regulamentação específica, estabeleceram caminhos próprios para a repartição de competências e funções do Estado e para a criação de arranjos e instrumentos de coordenação e cooperação entre as instâncias de governo. A política de saúde, por exemplo, desenvolveu, por um lado, regras e instrumentos que possibilitaram sua adaptação em nível estadual e impuseram

\footnotetext{
22 Segundo o art. 24 da Constituição Federal, a União tem a competência de estabelecer normas gerais que podem ser complementadas por legislação estadual, desde que estas não sejam contrárias às regras mais amplas. Os estados podem exercer competência legislativa plena somente nos casos de ausência de legislação federal sobre as normas gerais.
} 
ritmos e situações diferenciadas ao processo de descentralização do SUS, com flexibilidade para atender a situações de desigualdades das unidades subnacionais (Arretche, 2000). Por outro lado, possibilitou a criação e o fortalecimento de instâncias de negociação e a pactuação entre os gestores do SUS e o exercício da gestão compartilhada na saúde (Machado, Lima \& Baptista, 2007).

Porém, ao mesmo tempo que a questão da cooperação intergovernamental foi remetida para as políticas específicas, não foram revistos os espaços e mecanismos institucionais no âmbito mais geral da federação para gerar as condições políticas e econômicas necessárias à coordenação federativa. Compreendida como formas de integração, compartilhamento e decisão conjunta que resultam na instauração de parcerias aprovadas pelos governos (Abrucio, 2005), a coordenação é um elemento-chave para se garantir o equilibrio federativo. Para o seu fortalecimento é necessário a emergência de estruturas dedicadas à construção da relação centro/periferia, o reforço de burocracias eficientes nos diferentes níveis de governo, a existência de gestores intergovernamentais e o desenvolvimento de instrumentos de diplomacia que favoreçam o entendimento e o encaminhamento dos conflitos (Viana, Lima \& Oliveira, 2002). Estas questões extrapolam o escopo das políticas específicas e remetem a características mais estruturais do Estado e à sua forma de atuação.

Nesse sentido, chama atenção que a lei complementar para fixação das normas para cooperação não tenha entrado na agenda de discussões dos fóruns legislativos, nem tenha sido objeto de votação do Senado, câmara de representação dos estados por excelência e que deveria ter como foco as questões de interesse federativo. Mesmo no âmbito dos Executivos, há poucos espaços formais e não há tradição de debate e cultura de negociação política envolvendo os assuntos pertinentes à federação. ${ }^{23}$ Vale ainda mencionar que, até 2005, não existia no Brasil uma legislação específica que apontasse as formas de consorciamento entre os entes da federação. ${ }^{24}$ Somente em abril de 2005 foi aprovada a lei n. 11.107/2005, que dispõe sobre a contratação de consórcios públicos, regulamentada posteriormente através do decreto n. 6.017/2007 (Pedreira, 2007).

Por último, cabe enfatizar a importante 'assimetria existente entre os estados'. A desigualdade territorial é uma marca da nossa federação desde seu nascedouro, e até hoje não foi suficientemente enfrentada pelos sucessivos governos, tendendo a aumentar em face do processo atual de abertura da economia brasileira. Em que pesem as distâncias políticas e econômicas entre os estados, há uma tendência à adoção de regras uniformes

\footnotetext{
${ }^{23}$ Apenas em 2003, é criada uma estrutura no Executivo Federal - a Subchefia de Assuntos Federativos para auxiliar os governos, a Presidência e os ministros de Estado, nos programas e projetos pertinentes à federação.

${ }^{24}$ A ausência de lei específica não inibiu a constituição de consórcios intermunicipais no Brasil. Segundo Pedreira (2007), no ano de 2005, somente na saúde, havia, no país, 1.907 municípios (34,3\% do total) participando de consórcios. A autora sugere que, tendo em vista a fragilidade do ordenamento legal, são os próprios entes federativos que começam a reivindicar um tratamento jurídico mais adequado ao tema. A legislação recente sobre os consórcios públicos vem a atender a estas demandas, mas sua aplicação parece bastante complexa e suscita questionamentos em relação ao papel dos estados no processo.
} 
para as esferas subnacionais, em especial as instâncias estaduais, dificultando a adoção de políticas próximas a suas realidades e prioridades (Souza, 2005).

Noutro aspecto, o território, como elemento de síntese das desigualdades socioeconômicas existentes, não se apresentou como objeto principal de análise e planejamento para as diferentes áreas do governo durante toda a década de 1990, restringindo-se às políticas de desenvolvimento macrorregional (Gadelha et al., 2009). Tal postura embotou a capacidade política e técnica na construção de estratégias regionais e, de certo modo, possibilitou a acomodação de interesses. Para a saúde, o avanço limitado da lógica territorial na condução de políticas específicas repercutiu diretamente no processo de descentralização e na atuação dos estados (Viana et al., 2007).

O Quadro 1 resume os principais dilemas institucionais aqui pontuados para atuação dos estados.

Quadro 1 - Dilemas institucionais para atuação dos estados no Brasil

\begin{tabular}{|l|l|}
\hline \multicolumn{1}{|c|}{ DIMENSÕES DO FEDERALISMO } & \multicolumn{1}{c|}{ DileMAS PARA ATUAÇÃO DOS ESTADOS } \\
\hline POLITICA & $\begin{array}{l}\text { Predomínio de cultura política centralizadora } \\
\text { Fortalecimento dos municípios no sistema político } \\
\text { Pulverização e fragmentação do poder e interesses no âmbito local } \\
\text { Governabilidade reduzida dos estados } \\
\text { Limitações dos mecanismos de negociação intergovernamental } \\
\text { Insuficiência de mecanismos regulatórios entre os governos }\end{array}$ \\
\hline FISCAL & $\begin{array}{l}\text { Predomínio das relações fiscais entre a União e os municípios } \\
\text { Insuficiência dos mecanismos de equalização fiscal a cargo dos estados } \\
\text { Privilegiamento dos municípios na descentralização tributária } \\
\text { Endividamento e restrição da autonomia orçamentária dos entes } \\
\text { subnacionais } \\
\text { Guerra fiscal entre os estados }\end{array}$ \\
\hline ORGANIZACIONAL & $\begin{array}{l}\text { Número elevado de municípios brasileiros com limitações das condições } \\
\text { institucionais e políticas } \\
\text { Predomínio de competências comuns e concorrentes entre os governos } \\
\text { Insuficiência dos espaços e mecanismos de coordenação e cooperação } \\
\text { intergovernamental } \\
\text { Assimetria entre os governos subnacionais } \\
\text { Uniformidade das regras nacionais e pouco enfrentamento das } \\
\text { desigualdades territoriais com estratégias regionais }\end{array}$ \\
\hline
\end{tabular}

\section{O Papel da Esfera Estadual no Marco Legal e Normativo do SUS}

Em consonância com o exposto ao longo deste capítulo, considera-se importante compreender a definição sobre o papel da esfera estadual no arcabouço legal e normativo do SUS, considerando as funções do Estado na saúde: formulação de políticas e planejamento, financiamento, regulação e prestação de serviços. 
Empreender a análise do marco legal e normativo sugere de imediato uma compreensão mais específica da Constituição Federal Brasileira, entendida como norma fundamental do Estado e orientadora dos princípios que definem a ação dos órgãos supremos (Bercovici, 2004).

A CF88 é o marco legal que orienta o Estado brasileiro no exercício de suas funções na saúde. Na nova Carta, estão expressos os princípios, direitos e as garantias fundamentais do Estado, ${ }^{25}$ entre os quais se inclui o direito à saúde (art. 6). A explicitação do arranjo político-institucional setorial foi feita no âmbito da Lei Orgânica da Saúde (lei n. 8.080) e, de forma complementar, na lei n. 8.142, ambas aprovadas no ano de 1990 (Brasil, 1990a, 1990b). ${ }^{26}$ Assim, quando se trata de analisar as funções do Estado na saúde definidas para as três esferas de governo, tais leis (leis n. 8.080 e n. 8.142) se configuram como principal instrumento legal de análise.

Ainda no sentido de compreender o marco no qual as leis se inserem, devem-se considerar as emendas constitucionais à Carta de 1988 que modificam e introduzem inovações ao texto constitucional e que servirão de embasamento legal para as normativas do Estado. No caso em específico da saúde, é preciso incorporar a emenda constitucional 29 (EC29) aprovada no ano 2000, que, de modo específico, trata da função do financiamento da saúde. ${ }^{27}$

A EC29 (Brasil, 2000b) altera seis artigos da CF88 e acrescenta um artigo ao ato das disposições constitucionais transitórias com o objetivo de garantir a estabilidade no financiamento da saúde, definindo a participação das esferas de governo no aporte de recursos. Com a emenda, os estados passam a ter que aplicar, no mínimo, 12\% de suas receitas próprias em ações e serviços públicos de saúde, e os municípios, 15\%. No caso da União, a definição é mais frouxa suscitando maior precisão em regulamentação posterior. Ressalte-se que a emenda não logrou definir as "ações e serviços públicos de saúde", o que possibilitou a utilização dos recursos setoriais em outras áreas afins. Estados e municípios, desde a aprovação da EC29, passaram a aplicar mais recursos em saúde em termos percentuais, o que não significou, necessariamente, um maior aporte de recursos para as ações de saúde propriamente ditas. ${ }^{28}$

\footnotetext{
${ }^{25} \mathrm{Na}$ Carta, além dos princípios, direitos e garantias fundamentais do Estado, estão definidas as diretrizes sobre a organização do Estado e dos Poderes, as questões relativas à defesa do Estado e das instituições democráticas, a tributação e o orçamento, a ordem econômica, financeira e social (Brasil, 1988).

${ }^{26}$ A lei n. 8.142 (Brasil, 1990b) foi apresentada com o objetivo de recuperar alguns dos artigos da lei n. 8.080 (Brasil, 1990a) que estavam na proposição inicial aprovada pelo Congresso e que sofreu vetos do presidente Fernando Collor. Dentre os aspectos recuperados na lei n. 8.142 estão os relativos à participação popular e parte dos artigos referentes ao financiamento, especificamente no que se refere à transferência de recursos .

${ }^{27}$ O texto constitucional não definiu uma vinculação orçamentária para a saúde, apesar dos esforços empreendidos pelos grupos reformistas. O principal argumento contrário à vinculação estava na lógica orçamentário-tributária que defendia a flexibilidade da gestão pública. Ao final do debate inseriu-se, nas disposições transitórias da CF88, a definição de 30\% do orçamento da seguridade social a serem destinados para a saúde. Sobre as disputas em torno ao texto constituinte e a questão do financiamento, ver Baptista (1998) e Rodrigues Neto (2003).

28 Desde a aprovação da EC29 no ano 2000 tramita no Congresso Nacional uma nova proposta de Lei Complementar (Brasil, 2000a) com o objetivo de regulamentar a EC29 e esclarecer a definição de "ações e serviços públicos de saúde”, estabelecer percentuais mínimos para a União e critérios para transferência e uso dos recursos nos estados e municípios.
} 
Em síntese, é importante perceber que a CF88 define por meio de diretrizes gerais a proposta política de organização do sistema de saúde e que somente no ano 2000 a EC29 recupera uma função importante do Estado na saúde: o financiamento. No que tange à esfera estadual, o marco constitucional afirma sua responsabilidade na garantia do direito à saúde e sua participação no financiamento do sistema.

Com a Lei Orgânica da Saúde (LOS) detalham-se os princípios do SUS presentes na Constituição. A lei define a estratégia de organização do sistema e traduz em capítulos específicos as competências e atribuições das esferas de governo, a forma de funcionamento dos serviços privados de assistência à saúde, a política de recursos humanos e de financiamento (Brasil, 1990a). Pode-se dizer que a LOS é a expressão de uma dada visão estratégica de reforma do sistema de saúde historicamente datada.

Um primeiro aspecto a ressaltar sobre a estratégia desenhada é a aposta em um projeto de descentralização pautado na organização dos sistemas municipais: "descentralização político-administrativa, com direção única em cada esfera de governo com: a) ênfase na descentralização dos serviços para os municípios; b) regionalização e hierarquização da rede de serviços de saúde" (art. 7, inciso IX).

Quando são analisadas as competências e atribuições de cada esfera de governo pelas funções de Estado na saúde (Quadro 2), é possível perceber novamente a ênfase na descentralização municipalista remetendo aos estados o papel de coordenador do sistema - "À direção estadual do SUS compete promover a descentralização para os municípios dos serviços e das ações de saúde, acompanhar, controlar e avaliar as redes hierarquizadas do SUS" (art. 17, incisos I e II).

A delegação do papel de coordenador ao estado não significou a retirada de sua responsabilidade na garantia do direito à saúde, mas a compreensão de sua relevância para a articulação, o apoio, o controle e a avaliação dos municípios sob sua jurisprudência.

No que se refere à prestação de serviços, há um rol expressivo de atribuições definidas para os estados na LOS. Assim, os estados devem assumir funções específicas de referência para os municípios e de forma complementar, ou suplementar, quando necessário, às ações e aos serviços que caberiam ao município. Em relação ao financiamento, cabem aos estados o apoio financeiro aos municípios, a contrapartida orçamentária e a responsabilidade na administração de recursos municipais, quando estes não atendem aos requisitos para o recebimento das transferências federais do SUS.

O processo de planejamento e orçamento previsto na LOS se estende do nível local até o federal (lógica ascendente) e busca compatibilizar as necessidades da política com a disponibilidade de recursos (art. 36). Entretanto, não há explicitação da responsabilidade direta dos estados na formulação e planejamento de políticas loco-regionais. Vale ressaltar que, ainda na função de formulação de políticas e planejamento, considera-se a constituição de consórcios municipais sem qualquer participação dos estados na articulação dos mesmos (art. 10). Tais aspectos evidenciam lacunas quanto ao importante papel de condução e mediação política a ser exercido pelos estados na saúde. 
Quadro 2 - Competências e atribuições da esfera estadual nas leis n. 8.080/1990 e n. 8.142/1990 segundo funções na saúde

\begin{tabular}{|c|c|c|c|c|}
\hline $\begin{array}{l}\text { LEIS/FUNÇÕES DO } \\
\text { ESTADO NA SAÚDE }\end{array}$ & $\begin{array}{l}\text { Formulação } \\
\text { De Políticas e } \\
\text { Planejamento }\end{array}$ & FINANCIAMENTO & REGULAC̣ÃO & PRESTAÇÃO dE SERVIÇOS \\
\hline $\begin{array}{l}\text { LEI N. 8.080/1990 } \\
\text { LEI N. 8.142/1990 }\end{array}$ & $\begin{array}{l}\text { - Participar } \\
\text { da formulação } \\
\text { de políticas de } \\
\text { saneamento, insumos } \\
\text { e equipamentos em } \\
\text { saúde } \\
\text { - Elaborar o plano } \\
\text { de saúde sob } \\
\text { sua competência } \\
\text { e promover a } \\
\text { articulação da política } \\
\text { e dos planos de saúde } \\
\text { municipais } \\
\text { - Promover a } \\
\text { descentralização para } \\
\text { os municípios } \\
\text { - Prestar apoio técnico } \\
\text { aos municípios } \\
\text { - Acompanhar, } \\
\text { controlar e avaliar } \\
\text { redes hierarquizadas } \\
\text { do SUS }\end{array}$ & $\begin{array}{l}\text { - Administrar } \\
\text { recursos } \\
\text { orçamentários e } \\
\text { financeiros } \\
\text { - Elaborar proposta } \\
\text { orçamentária em } \\
\text { conformidade com o } \\
\text { plano } \\
\text { - Prestar apoio } \\
\text { financeiro aos } \\
\text { municípios } \\
\text { - Explicitar a } \\
\text { contrapartida de } \\
\text { recursos para a } \\
\text { saúde no respectivo } \\
\text { orçamento* } \\
\text { - Administrar } \\
\text { os recursos do } \\
\text { município quando } \\
\text { este não atende aos } \\
\text { requisitos* }\end{array}$ & $\begin{array}{l}\text { - Estabelecer normas } \\
\text { para o controle e } \\
\text { avaliação das ações e } \\
\text { serviços de saúde } \\
\text { - Formular normas } \\
\text { e estabelecer padrões } \\
\text { e procedimentos de } \\
\text { controle de qualidade } \\
\text { para produtos e } \\
\text { substâncias de } \\
\text { consumo humano } \\
\text { - Elaborar normas } \\
\text { para regular as } \\
\text { atividades de serviços } \\
\text { privados de saúde }\end{array}$ & $\begin{array}{l}\text { - Identificar hospitais } \\
\text { de referência e gerir } \\
\text { sistemas públicos de } \\
\text { alta complexidade, de } \\
\text { referência estadual e } \\
\text { regional } \\
\text { - Coordenar rede } \\
\text { estadual de laboratórios e } \\
\text { hemocentros e gerir suas } \\
\text { unidades } \\
\text { - Coordenar e executar, } \\
\text { em caráter complementar, } \\
\text { ações e serviços de } \\
\text { vigilância epidemiológica, } \\
\text { vigilância sanitária, } \\
\text { alimentação e nutrição e } \\
\text { de saúde do trabalhador } \\
\text { - Executar supletivamente } \\
\text { ações e serviços de saúde }\end{array}$ \\
\hline
\end{tabular}

*Previsto na lei n. 8.142 (Brasil, 1990b). Todas as demais atribuições do estado apresentadas no quadro estão definidas na lei n. 8.080 (Brasil, 1990a).

Obs: Na elaboração do quadro foram consideradas tanto as atribuições comuns das três esferas quanto as atribuicões específicas do estado.

Dada a importância assumida pela descentralização no marco legal da saúde e ao contexto de reformas dos anos 90 , esta passou a ser um dos eixos centrais na implementação do SUS. A descentralização da política de saúde tornou-se fortemente conduzida e regulada pelo Ministério da Saúde ao longo desses anos. A base da regulação federal utilizada foi a normatização, consubstanciada na edição anual de dezenas de portarias formuladas nas diversas áreas do Ministério e demais entidades federais - em geral associadas a mecanismos financeiros de incentivo ou inibição de políticas e práticas pelos gestores estaduais, municipais e prestadores de serviços. ${ }^{29}$

Sem desconsiderar a importância dos vários instrumentos utilizados e seus impactos sobre a gestão descentralizada do sistema de saúde, as Normas Operacionais (NO) do SUS

\footnotetext{
${ }^{29}$ Sobre essa base se associam outras formas de regulação, tais como: apoio e capacitação técnica dos gestores estaduais e municipais, divulgação de propostas e instrumentos técnicos de gestão, capacitação de recursos humanos para o SUS, controle e avaliação de sistemas, serviços e práticas, financiamento de pesquisas, regulação de mercados relacionados à saúde, implementação de novas estruturas de regulação da rede de serviços, entre outros (Machado, 2002).
} 
e, mais recentemente, o Pacto pela Saúde, ocuparam papel de destaque na estratégia de regulação nacional da descentralização. Nos anos 90, foram publicadas quatro Normas Operacionais Básicas (NOBs) de 1991, 1992 (similar à anterior) (Brasil/MS, 1991, 1992), de 1993 (Brasil/MS, 1993) e de 1996 (Brasil, 1997). Na década de 2000, foi publicada a Norma Operacional da Assistência à Saúde (Noas) nas versões 2001 e 2002 (Brasil/MS, 2001, 2002) e, em 2006, as portarias relativas ao Pacto pela Saúde (Brasil/MS, 2006).

De caráter transitório, as normas federais foram sendo detalhadas, alteradas e sucessivamente substituídas, apresentando diferenças importantes entre si. Em geral, definem diferentes atribuições gestoras - do nível federal, estadual e municipal - sobre as ações e os serviços prestados no âmbito do SUS, bem como as responsabilidades e modalidades de transferência de recursos federais de custeio e de remuneração de serviços. Dado o peso dos recursos federais para o financiamento da saúde, as portarias federais têm um valor fundamental na configuração do papel gestor e dos sistemas de saúde nas esferas subnacionais. No entanto, há de se considerar os limites dessas normativas, que não abrangem todas as dimensões e variáveis importantes para consolidação do SUS (Levcovitz, Lima $\&$ Machado, 2001).

O Quadro 3 traz um balanço sobre o papel do estado nas principais normas do SUS no período de 1990 a 2006. Ressalte-se que essas normas foram elaboradas em contextos político-institucionais específicos, refletindo momentos distintos da implantação do SUS e posições variadas dos atores políticos nacionais em relação ao processo de descentralização e papel das três esferas de governo do SUS. Tal consideração é importante para compreender as diferenças das normas quanto à concepção sobre o papel dos estados e quanto ao conteúdo das propostas apresentadas nesse âmbito. Todavia, é possível perceber indícios de certo continuum, no sentido de que cada norma incorpora elementos presentes nas anteriores - em termos de diretrizes e instrumentos - e busca avançar em relação a lacunas não resolvidas pelos dispositivos normativos (Viana, Lima \& Oliveira 2002). 


\begin{tabular}{|c|c|c|c|}
\hline 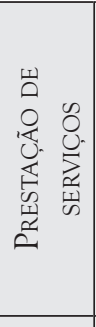 & 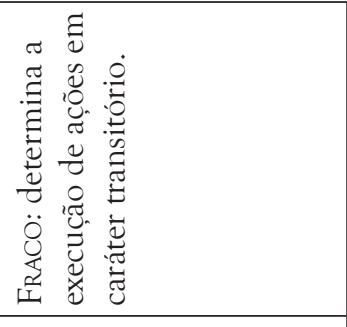 & 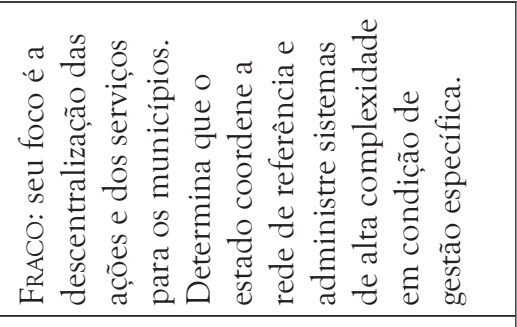 & 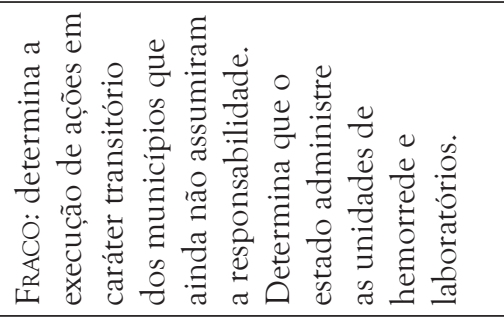 \\
\hline & 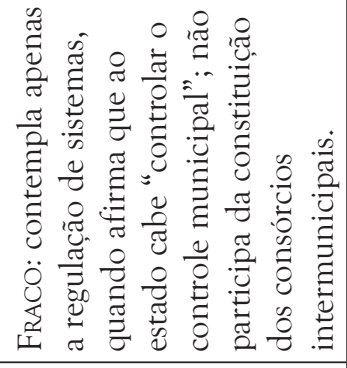 & 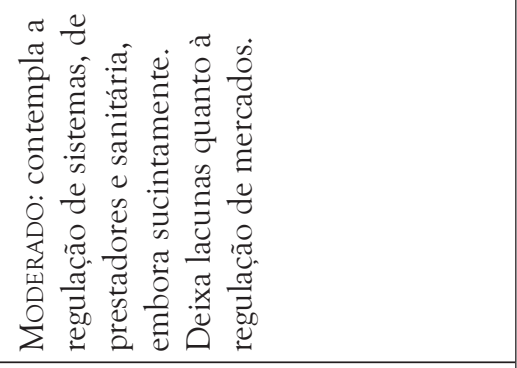 & 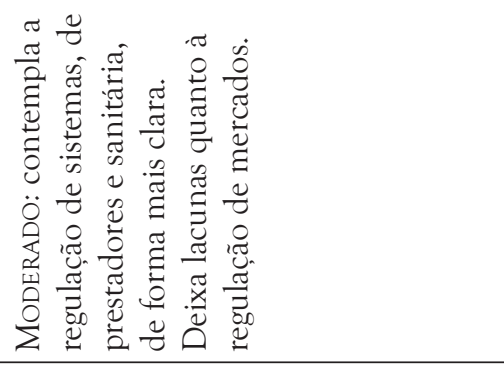 \\
\hline & 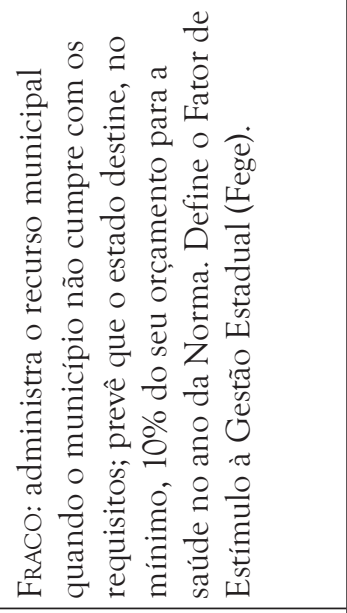 & 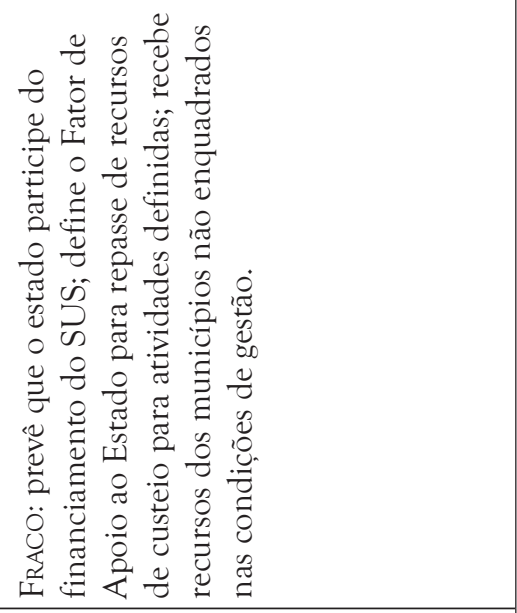 & 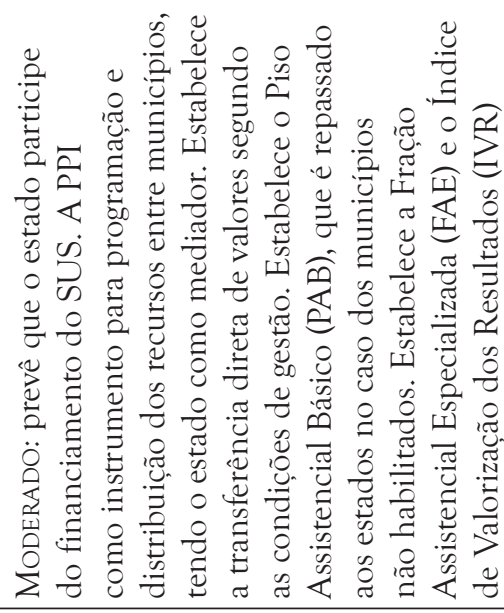 \\
\hline 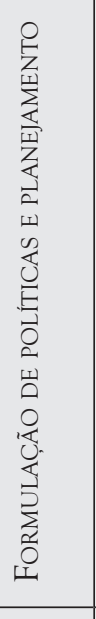 & 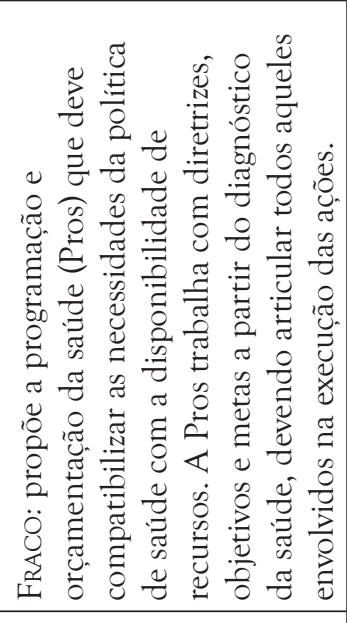 & 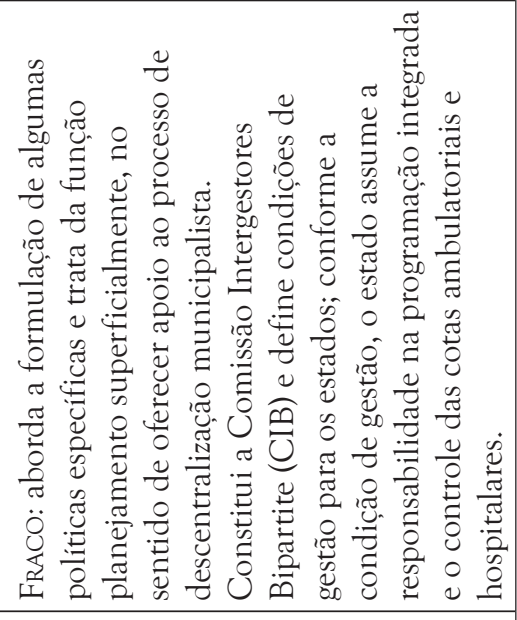 & 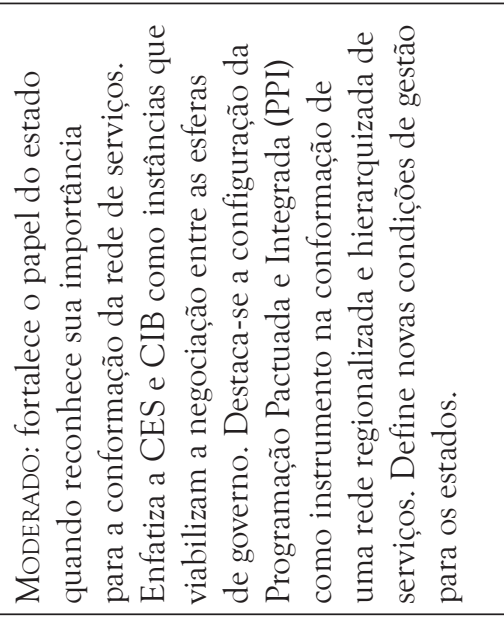 \\
\hline 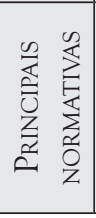 & 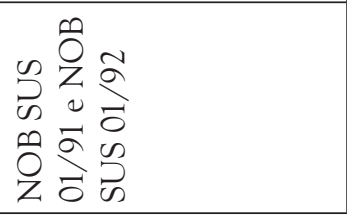 & 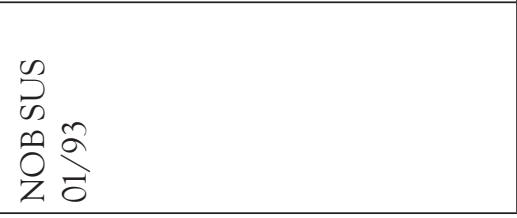 & 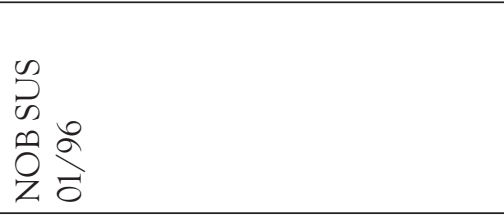 \\
\hline
\end{tabular}




\begin{tabular}{|c|c|c|}
\hline 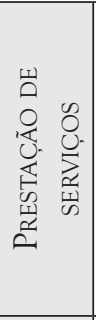 & 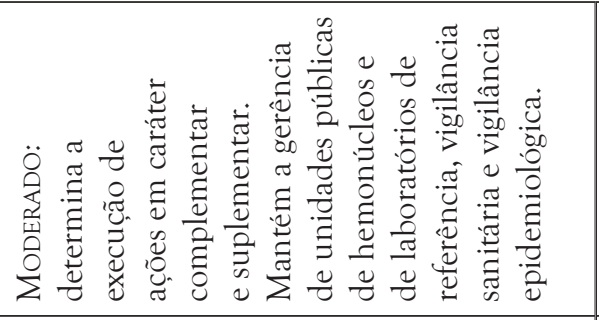 & 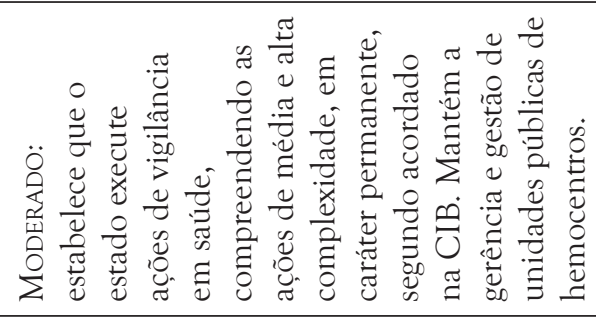 \\
\hline 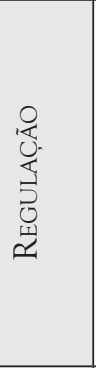 & 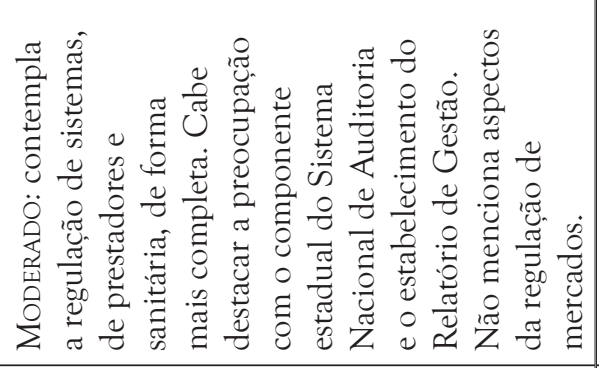 & 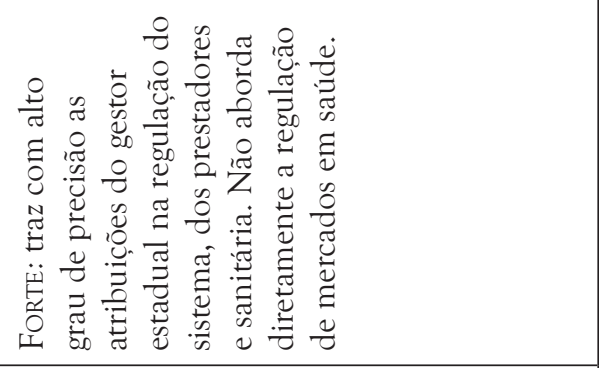 \\
\hline 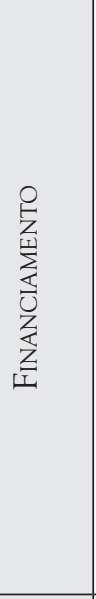 & 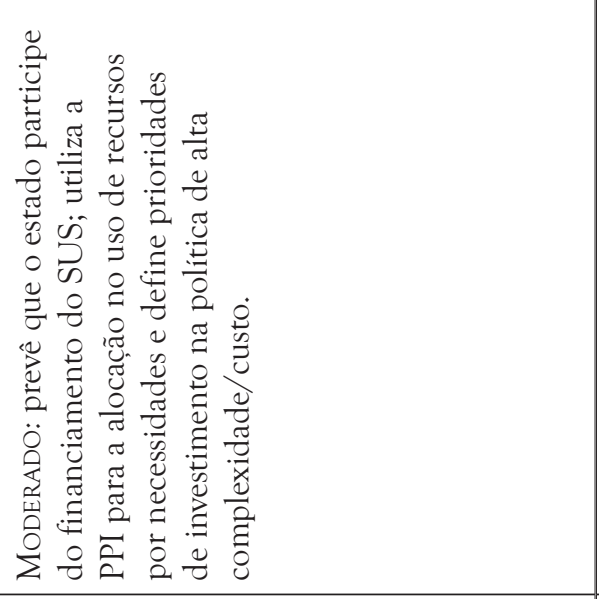 & 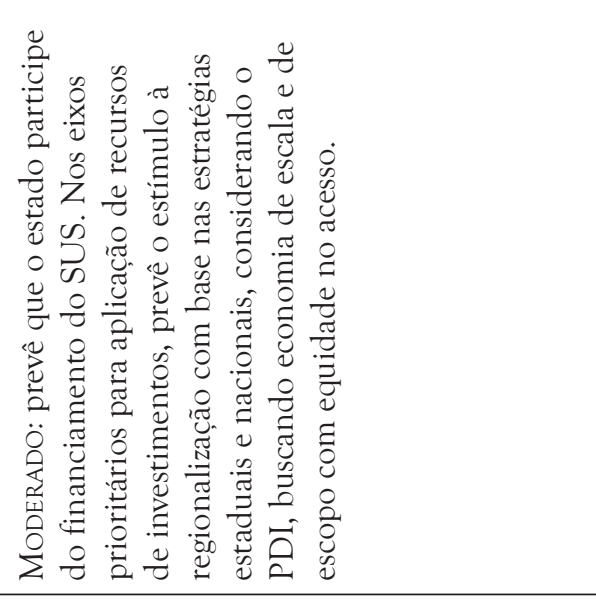 \\
\hline 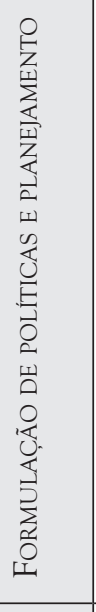 & 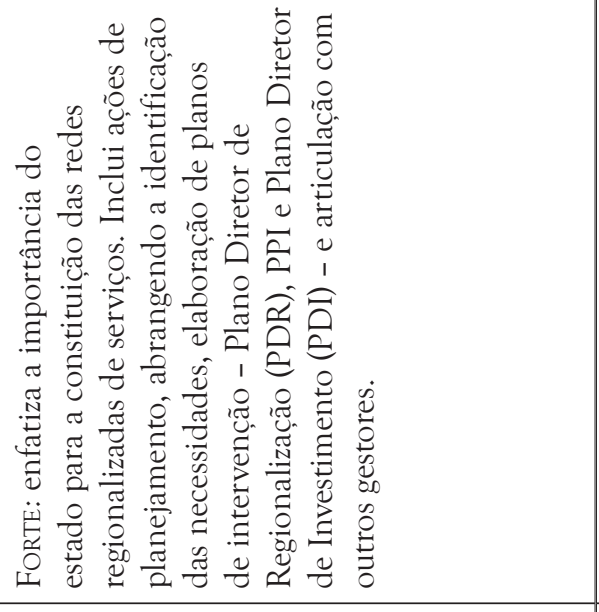 & 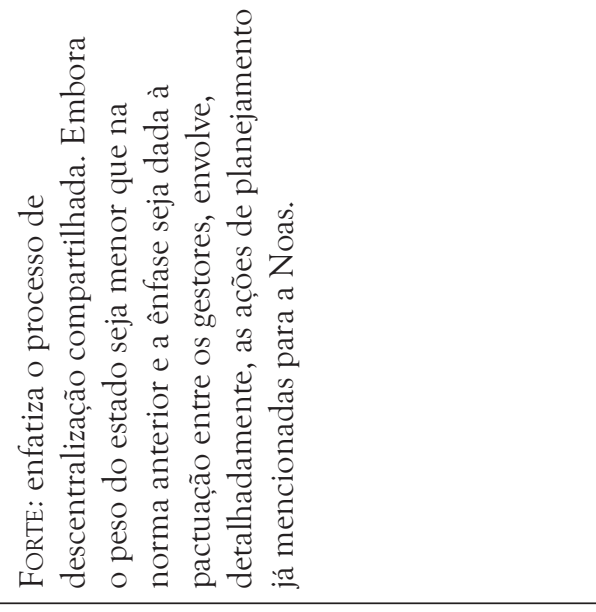 \\
\hline 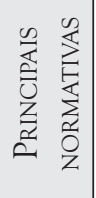 & 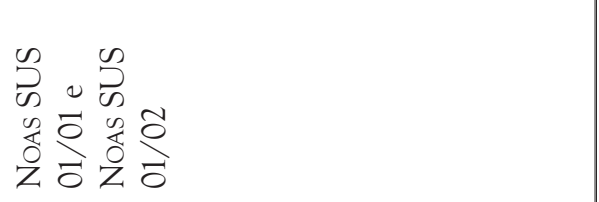 & 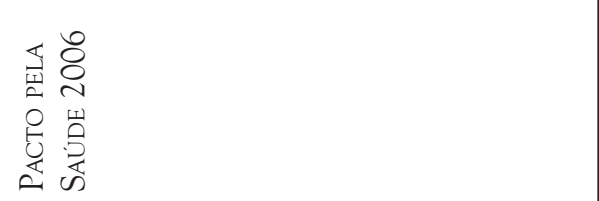 \\
\hline
\end{tabular}


A Norma Operacional Básica de 1991 (NOB SUS 01/91) foi a primeira do SUS, expressando as tensões relacionadas à tentativa de dar operacionalidade às diretrizes estabelecidas pelas leis da saúde recentemente promulgadas, em um contexto político adverso. Ademais, refletia o modus operandi do Inamps na condução das políticas ${ }^{30}$ e apresentava caráter tecnicista, enfocando aspectos relativos ao repasse de recursos federais da assistência. Em geral, a norma não propôs atribuições específicas para a esfera estadual, referindo-se a estados e municípios da mesma forma. Ao contrário, chega a propor a associação dos municípios por meio de consórcios, sem sequer mencionar um eventual papel dos estados. Pode-se dizer que o papel reservado aos gestores estaduais é limitado no que diz respeito às suas funções na saúde. Cabe a ressalva sobre a proposta de alguns dispositivos relativos ao financiamento - tema central da norma -, como a determinação de que os estados constituíssem fundos estaduais para o recebimento de recursos. ${ }^{31}$

A NOB SUS 01/92 trouxe de forma mais objetiva algumas atribuições próprias do nível estadual e outras em caráter de exceção. Comparada à norma anterior, mostrava uma tentativa de maior delineamento do papel dos estados. ${ }^{32}$ Cabe ponderar, no entanto, que a descentralização de cunho municipalista era enfatizada com consequências para a visão do papel da instância estadual, que permaneceu inespecífico e restrito em relação às várias funções.

A NOB SUS 01/93 teve como objeto o processo de municipalização. A regionalização era entendida como resultante de articulação e mobilização municipal, que devia considerar, acima de tudo, a vontade política dos municípios em se consorciar ou estabelecer qualquer outra relação de caráter cooperativo. Esta visão marcou a concepção predominante sobre o papel do estado, que seria, de certa forma, subsidiário, pautado pelo apoio à descentralização e aos municípios. A ênfase no caráter ascendente do planejamento é outra expressão dessa concepção. Assinale-se o reconhecimento do papel estadual na formulação e coordenação das políticas relacionadas ao tratamento fora do domicílio, medicamentos especiais, próteses e órteses ambulatoriais, e a previsão de transferências federais de custeio para os estados. ${ }^{33}$ Cabe destacar também a instituição da $\mathrm{CIB}^{34}$ como instância de negociação intergovernamental, o que deveria favorecer o

\footnotetext{
30 Tal norma, elaborada com pouca participação de estados e municípios em um momento delicado para a configuração inicial do sistema, foi oficializada mediante uma resolução do Inamps, que havia sido incorporado à estrutura da Secretaria Nacional de Assistência à Saúde do Ministério da Saúde, mas mantinha uma institucionalidade importante.

31 Tais dispositivos não foram implantados na ocasião, como vários outros presentes nas normas. No entanto, o texto se propõe nesse momento a caracterizar o conteúdo da normativa federal relativa ao papel dos estados. A questão da implementação será retomada adiante.

32 A NOB SUS 01/92 foi publicada como portaria da Secretaria Nacional de Assistência à Saúde. Nas suas considerações iniciais, menciona-se a relação do Ministério da Saúde com o Conass e o Conasems no estabelecimento de consensos sobre a política, incluindo o próprio conteúdo da norma. Isso pode ter influenciado as mudanças, ainda que tímidas, observadas em relação à NOB SUS 01/01.

${ }^{33}$ No entanto, essas transferências não foram implantadas como previstas.

${ }^{34}$ No processo de descentralização, as CIBs têm sido responsabilizadas pela adaptação das diretrizes nacionais às realidades regionais, propiciando a criação de acordos diversos entre os estados e municípios.
} 
compartilhamento de decisões quanto aos aspectos operacionais do SUS. Ainda assim, pode-se afirmar que a NOB SUS 01/93 não apontava soluções relativas à configuração de novas funções para as instâncias estaduais no SUS, nem definia instrumentos suficientes para esse processo.

A NOB SUS 01/96 foi elaborada por um grupo de atores críticos às limitações do processo de descentralização da primeira metade dos anos 90. Em relação às demais, procura ampliar o escopo da regulamentação incorporando não só orientações e instrumentos para a descentralização da assistência à saúde, como também para os campos de epidemiologia e controle de doença e vigilância sanitária. ${ }^{35}$ A norma visava a redefinir os papéis de cada esfera de governo, de modo que municípios e estados superassem o papel exclusivo de prestadores e assumissem efetivamente suas funções de gestores. No que diz respeito à esfera estadual, avançou ao buscar explicitar as atribuições dos estados no SUS e reconhecer os riscos de atomização do sistema na ausência da coordenação estadual. Ainda que tenha mantido a ênfase na descentralização para os municípios como forma de organização do sistema, destacava a importância do estado para harmonizar, integrar e modernizar os sistemas municipais. A PPI era o instrumento previsto para garantir a mediação do estado nas relações intermunicipais. Enfim, pode-se afirmar que a concepção dominante sobre o papel do estado na gestão do SUS sofre sua primeira inflexão com a promulgação desta NOB, o que se expressa principalmente nas proposições relativas às funções de formulação de políticas, planejamento e regulação.

A busca em resgatar o papel dos estados ficou ainda mais evidente com a elaboração da Noas, em suas versões 01/01 e 01/02, embora suas propostas fossem mais restritas ao campo da assistência à saúde. A Noas, ao trazer a regionalização para o centro do debate setorial, foi bastante detalhada na determinação das atribuições específicas do gestor estadual na condução desse processo, valorizando principalmente as funções estaduais de formulação de políticas, planejamento e regulação. De forma coerente com as diretrizes normativas, foram propostos instrumentos concretos para que o estado assumisse esse papel coordenador, tal como o PDR, o PDI e a própria PPI.

O Pacto pela Saúde (Brasil/MS, 2006) é bem detalhado nas atribuições do gestor estadual, embora o peso relativo dado ao seu papel seja menor do que o explicitado na Noas. ${ }^{36}$ Há dois aspectos destacados no Pacto relevantes para a análise de sua concepção e implicações sobre o papel estadual. O primeiro é a valorização do relacionamento entre os gestores das diferentes esferas de governo para a construção do SUS, no que tange à

\footnotetext{
${ }^{35}$ Machado (2007) destaca outras portarias e outros instrumentos que regulam o processo de descentralização da atenção à saúde incorporando os campos de vigilância epidemiológica e sanitária. Cabe enfatizar que, sob orientação de diretrizes distintas, os diversos campos da atenção à saúde seguiram caminhos próprios de descentralização com atribuições variadas da instância estadual.

${ }^{36}$ O Pacto, assim como a Noas, parte do reconhecimento da complexidade da construção do SUS diante da peculiaridade do arranjo federativo brasileiro pós-1988 e das imensas desigualdades regionais. A construção da proposta do Pacto a partir de 2003, no entanto, partiu de uma crítica contundente à excessiva rigidez normativa da Noas e buscou configurá-lo como uma estratégia mais flexível e adequada ao contexto federativo.
} 
regionalização e ao estabelecimento do sistema de referência intermunicipal e interestadual, considerando, inclusive, as regiões de divisas. Propõe-se que a regionalização oriente a descentralização das ações e dos serviços e potencialize os processos de planejamento e pactuação entre os gestores, de modo que o direito da população à saúde seja garantido. A regionalização do SUS é entendida como a construção de desenhos que respeitem as realidades locais, sendo propostos Colegiados de Gestão Regional (CGRs) como novos espaços de coordenação intergovernamental. O segundo é a ênfase no estabelecimento de compromissos formais entre gestores, traduzidos em planilhas com um conjunto de indicadores e metas a serem alcançadas.

O Pacto explicita, de forma bastante completa, uma série de atribuições da instância estadual, específicas ou não, relacionadas aos vários campos e funções na saúde. ${ }^{37} \mathrm{Em}$ contrapartida, apresenta duas limitações relevantes no que concerne ao papel dos estados. Uma é o fato de não ser embasado por um diagnóstico das condições de a esfera gestora realizar ou não as funções propostas e em quanto tempo. A segunda é a contradição existente entre, de um lado, a ênfase discursiva na regionalização e, de outro, a possibilidade de que os municípios possam celebrar seus compromissos de forma isolada, independentemente do planejamento e dos acordos constituídos em âmbito regional.

Ao estabelecer um balanço sobre o papel do estado no marco legal e normativo do SUS, percebe-se uma revalorização da instância estadual na saúde durante a década de 2000. Da mesma forma, identificam-se avanços quanto à concepção e relevância da regionalização na política de saúde. Isto porque, em que pesem os resultados positivos do processo de municipalização - a ampliação do acesso à saúde, a incorporação de práticas inovadoras no campo da gestão e da assistência à saúde e a incorporação de 'novos' atores que dão sustentabilidade política e financeira ao setor - permanecem, na atualidade, problemas relativos à iniquidade na oferta e no acesso, à intensa fragmentação e à desorganização de serviços devido à existência de milhares de 'sistemas locais isolados'.

A permanência desses problemas se deve, entre outros fatores, ao fato de extrapolarem a governabilidade das instâncias municipais e requererem a participação dos gestores estaduais na condução de estratégias que contemplem o planejamento e a consolidação de sistemas regionais de saúde. Sistemas regionais que, na sua maioria, não se coadunam com as fronteiras político-administrativas dos municípios, mas que favoreceriam a coordenação das ações e dos serviços de saúde no território.

\section{Considerações FINAIS: DESAFIOS PARA A ATUAÇÃo dAS INSTÂNCIAS ESTADUAIS NO PROCESSO DE REGIONALIZAÇÃO DO SUS}

A atuação dos estados na saúde pode ser mais bem compreendida se consideradas as condições institucionais moldadas pelas características de intervenção do Estado bra-

\footnotetext{
37 As responsabilidades dos estados estão organizadas no instrumento designado Termo de Compromisso da Gestão Estadual em sete eixos: gestão do SUS; regionalização; planejamento e programação; regulação, controle, avaliação e auditoria; gestão do trabalho; educação e saúde; e participação e controle social.
} 
sileiro, pelo pacto federativo e pelas peculiaridades da trajetória da política de saúde, que interferem no processo decisório dessas instâncias de governo.

Além dos dilemas institucionais mencionados neste capítulo, destacam-se desafios relativos ao próprio fortalecimento, à implantação da regionalização na política de saúde e à capacidade de os estados conduzirem esses processos em seu âmbito de competência. Cabe enfatizar que a regionalização, traduzida pela necessidade de formar redes de atenção à saúde nos diversos espaços geográficos da federação, apresenta inúmeros conflitos com a diretriz da descentralização, tal qual realizada até aqui. A regionalização tem natureza complementar e se forma a partir de elementos de diversidade; a descentralização tem natureza finalística, não complementar, formando-se pela redistribuição de responsabilidades e recursos para um ente específico. Considera-se que a tensão entre regionalização e descentralização da política de saúde acentuou-se no Brasil por pelos menos duas razões: a primeira é que, diferentemente de outros países, o planejamento regional não antecedeu os processos de descentralização. Pelo contrário, houve uma dissociação (ou um descolamento) entre a estratégia de descentralização e o projeto de regionalização logo no início de implantação do SUS; a segunda razão é que as propostas de regionalização têm início tardio, conformando-se após sucessivos ciclos de descentralização que tiveram como foco os milhares de municípios existentes.

Por essas razões, a regionalização, ao evocar maior responsabilidade das instâncias estaduais, pode gerar a necessidade de revisão de acordos desprovidos de racionalidade sistêmica estabelecidos durante a descentralização, indo de encontro a interesses já acomodados durante esse processo.

Dadas as características da federação brasileira - em que uma região de saúde pode abranger vários municípios e mais de um estado, englobar um município e sua periferia ou ser parte de um município -, a repartição de um território político-administrativo ou sua agregação em uma mesma região de saúde vai depender justamente das particularidades de cada município e/ou estado. Também não se pode desconsiderar que as fronteiras e os limites político-territoriais não funcionam como barreiras geográficas de proteção à saúde das pessoas, nem interrompem os fluxos de pacientes que porventura estejam à procura de serviços que atendam às suas necessidades e expectativas.

Dessa forma, é muito difícil separar de forma tão nítida os espaços territoriais de influência da atuação de cada esfera de governo. O processo de regionalização precisa admitir diferentes delimitações territoriais e a criação de mecanismos de gestão compartilhada da rede de serviços de saúde, com participação ativa da instância estadual na condução e mediação política dos processos de negociação intergovernamental que se façam necessários nas diversas regiões de saúde.

O SUS engloba um conjunto bastante amplo e diversificado de ações e prestadores de serviços, que conformam diferentes campos de atuação para as instâncias estaduais na saúde (assistência à saúde, vigilâncias, desenvolvimento e provisão de insumos para a saúde, formação de profissionais e gestão do trabalho em saúde). A diversidade de ações e serviços 
do SUS imprime diferentes lógicas de organização dos serviços de saúde no território que devem ser levadas em consideração pelos gestores estaduais no planejamento regional e na construção das regiões de saúde.

Outro aspecto a ser considerado diz respeito às imensas desigualdades socioeconômicas e territoriais que marcam a realidade brasileira e repercutem nas condições de saúde da população e no modo de vida das pessoas. A oferta de serviços no SUS também é bastante desigual, e as modalidades de atendimento que compõem o sistema não se distribuem uniformemente no espaço. Além disso, várias barreiras de acesso se impõem aos serviços em virtude das especificidades geográficas e da rede viária no Brasil.

As múltiplas realidades territoriais vão exigir o fortalecimento da lógica do planejamento regional bem como um esforço financeiro adicional dos estados, de modo a permitir uma diversificação de políticas e investimentos que relacionem as necessidades de saúde às dinâmicas territoriais específicas. Em contrapartida, as políticas setoriais só poderão ter viabilidade se articuladas a políticas de desenvolvimento regional de médio e longo prazo, tendo em vista a redução da iniquidade em diferentes planos.

Um último elemento a ser considerado diz respeito aos vários tipos de relações entre o segmento público e privado que configuram o sistema de saúde brasileiro. O SUS não é composto somente por serviços públicos, mas integra vários serviços privados, principalmente hospitais e unidades de diagnose e terapia, que são remunerados a partir dos recursos públicos destinados à saúde. Existem vários modelos de organização administrativa (consórcios, cooperativas, fundações, organizações sociais) e fortes interesses privados e corporativos que tornam complexos os mercados de prestação de serviços de saúde. Há também importante presença do segmento de planos e seguros de saúde e de 'serviços autônomos' em várias regiões do país.

Os tipos de relações público-privadas interferem na conformação da rede regionalizada de atenção à saúde. Por isso, a regulação dessas relações, orientada pela lógica pública e pelas necessidades de saúde da população, é um elemento fundamental a ser aprofundado pelas instâncias estaduais na condução da regionalização.

Tais características se apresentam de modo diferente em cada estado, mas alguns requisitos se colocam para o aprimoramento da gestão estadual do SUS em prol da regionalização: minorar a fragmentação e dar maior sustentabilidade ao sistema; recuperar a prática do planejamento estratégico e de longo prazo, que considere a base territorial e a realidade locoregional; superar a fragmentação interna, bem como carências institucionais das secretarias estaduais de saúde; promover uma efetiva articulação intergestores; assumir politicamente a condução do processo de regionalização; e cumprir funções específicas para seu avanço.

Cabe ponderar que o resgate do papel dos estados na gestão do SUS por meio da regionalização não representa, isoladamente, a solução para todos os desafios que se colocam para a atuação da esfera estadual na saúde. É preciso considerar o contexto político e econômico mais recente de mudanças relacionadas à inserção dos estados na federação brasileira, subjacente aos processos setoriais, o que constitui uma ampla agenda de pesquisa a ser desenvolvida. 


\section{ReFERÊNCIAS}

ABRUCIO, F. L. Os Barões da Federação: os governadores e a redemocratização brasileira. São Paulo: Hucitec, Departamento de Ciência Política da Universidade de São Paulo, 1998.

ABRUCIO, F. L. A reconstrução das funções governamentais no federalismo brasileiro. In: HOFMEISTER, W. \& CARNEIRO, J. M. B. (Orgs.). Federalismo na Alemanha e no Brasil. São Paulo: Fundação Konrad Adenauer Stiftung, 2001. v. I. (Série Debates, n. 22)

ABRUCIO, F. L. Reforma política e federalismo: desafios para a democratização brasileira. In: BENEVIDES, M. V.; KERCHE, F. \& VANNUCHI, P. (Orgs.). Reforma Politica e Cidadania. São Paulo: Fundação Perseu Abramo, 2003.

ABRUCIO, F. L. A coordenação federativa no Brasil: a experiência do período FHC e os desafios do governo Lula. Revista de Sociologia Política, 24: 41-67, 2005.

ABRUCIO, F. L. \& SAMUELS, D. A nova política dos governadores. Lua Nova, 40(41): 137-166, 1997.

ALMEIDA, C. Reforma de sistemas de servicios de salud y equidad en América Latina y el Caribe: algunas lecciones de los años 80 y 90. Cadernos de Saúde Pública, 18(4): 905-925, 2002.

ALMEIDA, M. H. T. Federalismo, democracia e governo no Brasil: idéias, hipóteses e evidências. Revista Brasileira de Informação Bibliográfica em Ciências Sociais (BIB), 51: 13-34, 2001.

ALMEIDA, M. H. T. Recentralizando a federação? Revista de Sociologia e Politica, 24: 29-40, 2005.

ALMEIDA, M. H. T. O Estado no Brasil contemporâneo. Um passeio pela história. In: MELO, C. R. \& SÁEZ, M. A. (Orgs.). A Democracia Brasileira: balanço e perspectivas para o século XXI. Belo Horizonte: Editora UFMG, 2007.

ARRETCHE, M. T. S. Estado Federativo e Políticas Sociais: determinantes da descentralização. Rio de Janeiro, São Paulo: Revan, Fapesp, 2000.

BANTING, K. \& CORBETT, S. Federalismo y políticas de atención a la salud. In: AUCLAIR, C.; CARRASCO, C. \& GADSDEN, H. (Eds.). Federalismo y Politicas de Salud: descentralización y relaciones intergubernamentales desde una perspectiva comparada. Ottawa, Ciudad de México: Foro de Federaciones, Instituto Nacional para el Federalismo y Desarrollo Municipal, 2002.

BAPTISTA, T. W. F. Seguridade social no Brasil. Revista do Serviço Público, 49(3): 99-118, 1998.

BERCOVICI, G. Constituição e política: uma relação difícil. Lua Nova, 61: 5-14, 2004.

BOSCHI, R. Capacidades estatais e políticas de desenvolvimento no Brasil. Tendências recentes. In: MELO, C. R. \& SÁEZ, M. A. (Orgs.). A Democracia Brasileira: balanço e perspectivas para o século XXI. Belo Horizonte: Editora UFMG, 2007.

BOSCHI, R. \& LIMA, M. R. S. O Executivo e a construção do Estado no Brasil: do desmonte da era Vargas ao novo intervencionismo regulatório. In: VIANNA, L. W. (Org.). A Democracia e os Três Poderes no Brasil. Belo Horizonte, Rio de Janeiro: Editora UFMG, Iuperj, Faperj, 2003.

BRASIL. Constituição da República Federativa do Brasil: promulgada em 5 de outubro de 1988. Brasília: Senado Federal, 1988. Disponível em: 〈www.senado.gov.br/bdtextual/const88/Con1988br.pdf〉. Acesso em: mar. 2008.

BRASIL. Lei Orgânica da Saúde - lei n. 8.080, de 19 set. 1990. Dispõe sobre as condições para a promoção, proteção e recuperação da saúde, a organização e o funcionamento dos serviços correspondentes e dá outras providências. Diário Oficial da União, Brasília, 20 set. 1990a, p. 18.055. Disponível em: 〈www6.senado.gov.br/sicon/ExecutaPesquisaLegislacao.action〉. Acesso em: mar 2008.

BRASIL. Lei n. 8.142, de 28 dez. 1990. Dispõe sobre a participação da comunidade na gestão do Sistema Único de Saúde - SUS e sobre as transferências intergovernamentais de recursos financeiros na área da saúde e dá outras providências. Diário Oficial da União, Brasília, 31 dez. 1990b, p. 25.694. Disponível em: 〈www6.senado.gov.br/sicon/ExecutaPesquisaLegislacao.action>. Acesso em: mar 2008. 
BRASIL. Norma Operacional Básica do Sistema Único de Saúde/NOB-SUS 96: gestão plena com responsabilidade pela saúde do cidadão. Brasília: Ministério da Saúde, 1997.

BRASIL. Lei Complementar n. 101 de 4 maio 2000. Estabelece normas de finanças públicas voltadas para a responsabilidade na gestão fiscal e dá outras providências. Diário Oficial da União, Brasília, 05 maio 2000a, p. 1. Disponível em: <www6.senado.gov.br/sicon/ExecutaPesquisaLegislacao. action>. Acesso em: mar 2008.

BRASIL. Emenda Constitucional n. 29, de 13 set. 2000. Altera os artigos 34, 35, 156, 160, 167 e 198 da Constituição Federal e acrescenta artigo ao Ato das Disposições Constitucionais Transitórias, para assegurar os recursos mínimos para o financiamento das ações e serviços públicos de saúde. Diário Oficial da União, Brasília, 14 set. 2000b. Disponível em: <www.presidencia.gov.br/ccivil/ Constituicao/Emendas/Emc/emc29.htm>. Acesso em: mar 2008.

BRASIL. Ministério da Saúde. Instituto Nacional de Assistência Médica da Previdência Social. Resolução n. 258, de 07 jan. 1991. Diário Oficial da União, Brasília, 10 jan. 1991.

BRASIL. Ministério da Saúde. Instituto Nacional de Assistência Médica da Previdência Social. Norma Operacional Básica do Sistema único de Saúde/NOB-SUS 92. Brasília: Ministério da Saúde, Instituto Nacional de Assistência Médica da Previdência Social, 1992.

BRASIL. Ministério da Saúde. Descentralização das Ações e Serviços de Saúde: a ousadia de cumprir e fazer cumprir a lei. Brasília: Ministério da Saúde, 1993.

BRASIL. Ministério da Saúde. Portaria MS/GM n. 95, de 26 jan. 2001. Aprova a norma operacional da assistência à saúde - NOAS-SUS 01/01. Diário Oficial da União, Brasília, 26 jan. 2001.

BRASIL. Ministério da Saúde. Secretaria de Assistência à Saúde. Departamento de Descentralização da Gestão da Assistência. Regionalização da Assistência à Saúde: aprofundando a descentralização com eqüidade no último acesso. Brasília: Ministério da Saúde, 2002. (Norma Operacional da Assistência à Saúde: NOAS-SUS 01/02 e Portaria MS/GM n. 373, de 27 fev. 2002 e regulamentação complementar).

BRASIL. Ministério da Saúde. Secretaria Executiva. Departamento de Apoio à Descentralização. Coordenação-Geral de Apoio à Gestão Descentralizada. Diretrizes Operacionais dos Pactos pela Vida, em Defesa do SUS e de Gestão. Brasília: Ministério da Saúde, 2006. (Série A: Normas e Manuais Técnicos) BREMAEKER, F. E. J. Evolução do Quadro Municipal Brasileiro no Período entre 1980 e 2001. Rio de Janeiro: Instituto Brasileiro de Administração Municipal, 2001. (Série Estudos Especiais, n. 20).

BURGESS, M. Federalism and federation: a reappraisal. In: BURGESS, M. \& GAGNON, A. G. (Orgs.). Comparative Federalism and Federation: competing traditions and future directions. Toronto: University of Toronto, 1993.

CARVALHO, J. M. Federalismo y centralización em el império Brasileño: historia y argumento. In: CARMAGNANI, M. et al. (Coord.) Federalismos Latinoamericanos: México, Brasil, Argentina. México: El Colégio de México, Fondo de Cultura Econômica, 1996.

COSTA, V. Federalismo. In: AVELAR, L. \& CINTRA, A. O. (Orgs.). Sistema Político Brasileiro: uma introdução. Rio de Janeiro, São Paulo: Fundação Konrad-Adenauer-Stiftung, Editora da Unesp, 2004.

DAIN, S. Dilemas do Estado diante da nova ordem econômica e social. In: VALLADARES, L. \& COELHO, M. P. (Orgs.). Governabilidade e Pobreza no Brasil. Rio de Janeiro: Civilização Brasileira, 1995.

DALlARI, S. G. Os Estados Brasileiros e o Direito à Saúde. São Paulo: Hucitec, 1995.

DANIEL, C. \& SOMEKH, N. Gestão compartilhada, limites e possibilidades: a experiência do Grande ABC. In: FUNDAÇÃO PREFEITO FARIA LIMA. (Org.). Consórcio: uma forma de cooperação intermunicipal. São Paulo: Fundação Prefeito Faria Lima, Cepam, Unidades de Políticas Públicas, 2001.

DOLHNIKOFF, M. O Pacto Imperial: origens do federalismo no Brasil do século XIX. São Paulo: Globo, 2005.

DRAIBE, S. Uma nova institucionalidade das políticas sociais? Reflexões a respeito da experiência latino-americana recente de reformas dos programas sociais. São Paulo em Perspectiva- Fundação Seade, 11(4): 3-15, 1997. 
ELAZAR, D. J. Exploring Federalism. Tuscaloosa: University of Alabama, 1987.

EVANS, P. O Estado como problema e solução. Lua Nova, 28/29: 107-156, 1993.

FERRERA, M. Le Trappole del Welfare. Bologna: Il Mulino, 1998.

FIGUERAS, J. et al. Retos para los sistemas sanitarios de Latinoamérica: que puede aprenderse de la experiencia europea? Gaceta Sanitaria, 16(1): 5-17, 2002

FIORI, J. L. (Org.). Estados e Moedas no Desenvolvimento das Nações. Petrópolis: Vozes, 1999.

FONSECA, C. M. O. Saúde no Governo Vargas (1930-1945). Rio de Janeiro: Editora Fiocruz, 2007.

FRANCE, G. Federalismo fiscal: experiências internacionais e modelo para a Itália. In: NEGRI, B. \& VIANA, A. L. D. (Orgs.). O SUS em Dez Anos de Desafios. São Paulo: Sobravime, Cealag, 2002.

GADELHA, C. A. G. et al. Saúde e desenvolvimento: uma perspectiva territorial. In: VIANA A. L. D.; ELIAS P. E. M. \& IBAÑEZ N. (Orgs.). Saúde, Desenvolvimento e Território. São Paulo: Hucitec, 2009.

GOMES, G. M. \& MAC DOWELL, M. C. Descentralização Política, Federalismo Fiscal e Criação de Municípios: o que é mau para o econômico nem sempre é bom para o social. Brasília: Ipea, 2000. (Texto para Discussão, n. 706).

GOULART, F. A. A. Municipalização Veredas: caminhos do movimento municipalista de saúde no Brasil. Rio de Janeiro: Abrasco, Conasems, 1996.

KUGELMAS, E. \& SOLA, L. Recentralização/descentralização: dinâmica do regime federativo no Brasil dos anos 90. Tempo Social, 11(2): 63-83, 1999.

LENHARDT, G. \& OFFE, C. Teoria do Estado e política social. In: OFFE, C. Problemas Estruturais do Estado Capitalista. Rio de Janeiro: Tempo Brasileiro, 1984.

LEVCOVITZ, E.; LIMA, L. D. \& MACHADO, C. V. Política de saúde nos anos 90: relações intergovernamentais e papel das normas operacionais básicas. Revista Ciência $\mathcal{E}$ Saúde Coletiva, 6(2): 269-291, 2001.

LIMA, L. D. Federalismo, Relações Fiscais e Financiamento do Sistema Único de Saúde: a distribuição de receitas vinculadas à saúde nos orçamentos municipais e estaduais. Rio de Janeiro: Museu da República, 2007.

LOPREATO, F. L. C. O endividamento dos governos estaduais nos anos 90. Economia e Sociedade, 15: 117-158, 2000.

MACHADO, C. V. Regulação da política nacional de saúde: estratégias e tendências. In: NEGRI, B. \& VIANA, A. L. D. (Orgs.). O SUS em Dez Anos de Desafio. São Paulo: Sobravime, Cealag, 2002.

MACHADO, C. V. O modelo de intervenção do Ministério da Saúde nos anos 90. Cadernos de Saúde Pública, 23(9): 2.113-2.126, 2007.

MACHADO, C. V.; LIMA, L. D. \& BAPTISTA, T. W. F. Configuração institucional e o papel dos gestores no Sistema Único de Saúde. In: MATTA, G. C. \& PONTES, A. L. M. (Orgs.). Políticas de Saúde: a organização e a operacionalização do Sistema Único de Saúde. 1. ed. Rio de Janeiro: EPSJV/ Fiocruz, 2007.

MAJONE, G. Do Estado positivo ao estado regulador: causas e consequências de mudanças no modo de governança. Revista do Serviço Público, 1: 5-36, 1999.

MARQUES, E. Notas críticas à literatura sobre Estado, políticas estatais e atores políticos. Revista BIB, 43: 67-102, 1997.

MESQUITA, A. C. S. Crise do Estado Nacional Desenvolvimentista e Ajuste Liberal: a difícil trajetória de consolidação do Sistema Único de Saúde - SUS (1988/2007), 2008. Dissertação de Mestrado, Campinas: Instituto de Economia, Universidade Estadual de Campinas.

MORA, M. O Processo de Endividamento dos Estados: problemas e limites à descentralização e à autonomia, 1998. Dissertação de Mestrado, Rio de Janeiro: Instituto de Economia, Universidade Federal do Rio de Janeiro. 
MORA, M. \& VARSANO, R. Fiscal Decentralization and Subnational Fiscal Autonomy in Brazil: some facts of the nineties. Brasília: Ipea, 2001. (Texto para Discussão, n. 854).

ORGANIZACIÓN PAN AMERICANA DE LA SALUD (OPAS). Salud en las Américas -2007. Washington: Opas, 2007.

PEDREIRA, R. S. Os Consórcios Intermunicipais de Saúde no Brasil: contexto, panorama e regulamentação recente, 2007. Monografia de Especialização, Rio de Janeiro: Escola Nacional de Saúde Pública Sergio Arouca, Fundação Oswaldo Cruz.

PIERSON, P. The New Politics of the Welfare State. New York: Oxford University Press, 2000.

PRADO, S. Distribuição intergovernamental de recursos na federação brasileira. In: REZENDE, F. \& OLIVEIRA, F. A. (Orgs.). Descentralização e Federalismo Fiscal no Brasil: desafios da reforma tributária. Rio de Janeiro: Konrad Adenauer, 2003.

PRADO, S. \& CAVAlCANTI, C. E. G. A Guerra Fiscal no Brasil. São Paulo, Brasília: Fundap, Fapesp, Ipea, 2000.

PRADO, S.; QUADROS, W. \& CAVALCANTI, C. E. Partilha de Recursos na Federação Brasileira. São Paulo, Brasília: Fapesp, Fundap, Ipea, 2003.

REZENDE, F. Modernização tributária e federalismo fiscal. In: REZENDE, F. \& OLIVEIRA, F. A. (Orgs.). Descentralização e Federalismo Fiscal no Brasil: desafios da reforma tributária. Rio de Janeiro: Konrad Adenauer, 2003.

REZENDE, F. \& AFONSO, J. R. R. A Federação Brasileira: fatos, desafios e perspectivas, dez. 2001. Disponível em: 〈www.federativo.bndes.gov.br/bf_bancos/estudos/e0002426.pdf>. Acesso em: mar. 2008.

RODRIGUEZNETO, E. Saúde: promessas e limites da Constituição. Rio de Janeiro: Editora Fiocruz, 2003.

SALLUM, J. B. Crise, democratização e liberalização no Brasil. In: SALLUM JR., B. (Org.). Brasil e Argentina Hoje: política e economia. Bauru: Edusc, 2004.

SANTOS, W. G. O ex-Leviatã Brasileiro. Rio de Janeiro: Civilização Brasileira, 2006.

SOARES, M. M. Federação, democracia e instituições políticas. Lua Nova, 44:137-163, 1998.

SOUZA, C. Governos e sociedades locais em contextos de desigualdades e de descentralização. Revista Ciência E⿱ Saúde Coletiva, 7(3): 431-442, 2002.

SOUZA, C. Federalismo, desenho constitucional e instituições federativas no Brasil pós-1988. Revista de Sociologia e Política, 24: 105-121, 2005.

STEPAN, A. Para uma nova análise comparativa do federalismo e da democracia: federações que restringem ou ampliam o poder do demos. Dados-Revista de Ciências Sociais, 42(2): 197-251, 1999.

TAVARES, M. C. \& FIORI, J. L. (Orgs.). Poder e Dinheiro: uma economia política da globalização. Petrópolis: Vozes, 1997.

VARSANO, R. A Evolução do Sistema Tributário Brasileiro ao Longo do Século: anotações e reflexões para futuras reformas. Brasília: Ipea, 1996. (Texto para Discussão, n. 405)

VIANA, A. L. D.; LIMA, L. D. \& OLIVEIRA, R. G. Descentralização e federalismo: a política de saúde em novo contexto - lições do caso brasileiro. Revista Ciência Ė Saúde Coletiva, 7(3): 493-507, 2002.

VIANA, A. L. D. et al. Sistema de saúde universal e território: desafios de uma política regional para a Amazônia Legal. Cadernos de Saúde Pública, 23, supl. 2:. S117-S131, 2007.

WILENSKY, H. L. Rich Democracies: political economy, public policy and performance. Berkeley: Universety of California Press, 2002. 